\title{
Efficacy of a sheet pile wall as a wave barrier for railway induced ground vibration 类, 类蛇
}

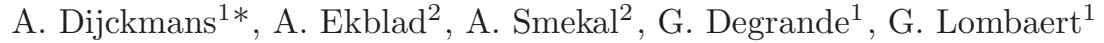 \\ ${ }^{1}$ KU Leuven, Department of Civil Engineering, Kasteelpark Arenberg 40, B-3001 Leuven, Belgium \\ 2 Trafikverket, 40533 Göteborg, Sweden
}

\begin{abstract}
This paper investigates the effectiveness of a sheet pile wall to reduce railway induced vibration transmission by means of field measurements and numerical simulations. At Furet, Sweden, a sheet pile wall has been installed in the soil near the track to reduce train induced vibrations in houses close to the track. The depth of the sheet piles is $12 \mathrm{~m}$ with every fourth pile extended to $18 \mathrm{~m}$. The efficacy of the wall is determined from in situ measurements of free field vibrations during train passages before and after installation of the sheet pile wall. The field test shows that the sheet pile wall reduces vibrations from $4 \mathrm{~Hz}$ upwards. Up till $16-20 \mathrm{~Hz}$, the performance generally increases with frequency and typically decreases with increasing distance behind the wall. The performance is further studied by means of two-and-a-half-dimensional coupled finite element - boundary element models. The sheet pile wall is modeled as an orthotropic plate using finite elements, while the soil is modeled as a layered halfspace using boundary elements. The sheet pile wall acts as a stiff wave barrier and the efficacy is determined by the depth and the stiffness contrast with soil. The reduction of vibration levels is entirely due to the relatively high axial stiffness and plate bending stiffness with respect to the horizontal axis of the sheet pile wall; the plate bending stiffness with respect to the vertical axis is too low to affect the transmission of vibrations. Therefore, it is important to take into account the orthotropic behaviour of the sheet pile wall. It is concluded that a sheet pile wall can effectively act as a wave barrier in soft soil conditions provided that the wall is sufficiently deep.

Keywords: ground-borne vibration, sheet pile wall, wave barrier, 2.5D modelling, coupled finite element boundary element models.

\footnotetext{
Postprint submitted to Soil Dynamics and Earthquake Engineering

解 Published version: A. Dijckmans, A. Ekblad, A. Smekal, G. Degrande and G. Lombaert. Efficacy of a sheet pile wall as a wave barrier for railway induced ground vibration. Soil Dynamics and Earthquake Engineering, 84:55-69, 2016. http://dx.doi.org/10.1016/j.soildyn.2016.02.001

*Corresponding author. Phone: + 32163777 96. Fax: + 3216321988.

Email address: arne.dijckmans@bwk.kuleuven.be (A. Dijckmans ${ }^{1 *}$ )
} 


\section{Introduction}

Railway induced ground vibration can be a source of annoyance for lineside residents. Vibration in buildings $(1-80 \mathrm{~Hz})$ may cause malfunctioning of sensitive equipment and lead to discomfort of inhabitants. The vibrating walls and floors also radiate low frequency noise in the frequency range $16-250 \mathrm{~Hz}$. In case of excessive vibration levels, mitigation measures can be taken at the source, on the transmission path, or at the building where vibration problems occur $[1,2]$. In general, the mitigation of low frequency feelable vibration which involves surface waves with longer wavelengths and larger penetration depths is far more difficult [3] than the mitigation of high frequency ground vibration leading to ground-borne noise. Many of the mitigation measures at source, like soft railpads [4] and under-sleeper pads [5], will mainly lead to a reduction in the frequency range of relevance to ground-borne noise. Initial numerical analysis and preliminary experiments show that mitigation measures on the transmission path offer the prospect of obtaining vibration reduction at low frequencies [3]. In addition, interventions on the propagation path between source and receiver have the advantage that no modifications of the track are required. These measures include open and in-filled trenches $[6,7]$, wave impeding blocks $[8,9]$ and heavy masses on the soil's surface $[1,10,11]$.

The efficacy of open and in-filled trenches has been studied both by means of analytical models [12], finite element (FE) models [13], boundary element (BE) models [14, 15] and coupled FE-BE models [8, 16]. In the case of a homogeneous halfspace, an open trench proves effective when the depth is at least 0.6 times the Rayleigh wavelength in the soil $[6,17]$. The location and width of the trench are of secondary importance [17]. The isolation effectiveness typically decreases with distance, as wave diffraction can occur around the bottom of the trench $[7,18]$. The presence of shallow soft soil layers, often only about $2 \mathrm{~m}$ deep, leads to increased vibration propagation at frequencies where surface waves can propagate predominantly in these layers [18]. In this case, an open trench can already be effective when the trench cuts through the upper layers $[19,20]$. The practical application of vertical open trenches is limited to shallow depths, however, for stability reasons and the presence of groundwater. More practical realisations of trenches with sloping sides or a retaining structure have been investigated as well $[18,21]$. These studies indicate that the retaining structure can significantly reduce the efficacy.

To increase the depth and improve durability, trenches with soft or stiff in-fill materials can be used as a wave barrier. In general, in-filled trenches are less effective than open trenches $[8,16,17,20]$. While the efficacy of open trenches is mainly determined by their depth, the ratio between the bending stiffness of the barrier and the soil proves crucial for stiff wave barriers $[6,7,22,23,24]$. Therefore, stiff wave barriers are mostly effective at soft soil sites. For trenches filled with a soft material, the vibration isolation efficiency is mainly determined by their depth and the stiffness contrast between barrier and soil [20,25]. The vibration isolation is improved by increasing the width of the barrier or decreasing the Young's modulus of the soft 
in-fill material [20, 26].

Most numerical studies are based on two-dimensional (2D) or two-and-a-half-dimensional (2.5D) analysis assuming a barrier of infinite length. Three-dimensional (3D) analysis has also been used to investigate the influence of the finite length of open trenches and concrete barriers [27]. Coulier et al. [28] showed that diffraction effects occur around the edges of an open trench or stiff wave barrier with finite length, with a limited effect for a source at a fixed, central location. Full 3D models have also been used to study the effect of a row of piles with different separation distances [29, 30, 31]. Kattis et al. [32] presented an equivalent isotropic wave barrier model for a row of circular or square piles.

Although numerous numerical studies of open trenches and wave barriers have been reported, the number of full scale experiments is small. First experimental results on open trenches have been reported by Woods [33], Dolling [34] and Richart et al. [35]. These tests confirmed that an open trench starts to be effective if the depth is large enough compared to the Rayleigh wavelength. Klein et al. [15] performed tests on a $2 \mathrm{~m}$ deep trench with sloping sides, showing that the influence of the distance between source and trench is small. More recently, Alzawi et al. [36] presented full scale tests of a $20 \mathrm{~m}$ deep and $3 \mathrm{~m}$ wide open trench where a harmonic shaker was used as a vibration source. Afterwards, the trench was filled with geofoam, showing an overall reduction in effectiveness of $50 \%$. Other realisations of soft wave barriers include screens made of inflated gas cushions [37, 38], rubber chip barriers [39], and PUR sandwich panels [40]. The obtained reduction in practice is generally less than predicted, but well-designed barriers can approach the theoretical effectiveness of an open trench [38]. Vibration reduction measurements for an $8 \mathrm{~m}$ deep composite vibration screen, consisting of an expanded polysyrene core and concrete side panels, installed near a tramway in Belgium, showed a limited performance [25]. Scale model tests on concrete barriers have been performed by Haupt [23]. Çelebi et al. [41] compared the vibration isolation of a $3 \mathrm{~m}$ long and $2.5 \mathrm{~m}$ deep concrete filled trench with that of an open trench, a water filled trench, and a bentonite filled trench. It was found in these studies that concrete barriers, like soft wave barriers, can reduce vibrations but are less effective than open trenches. Full scale tests of stiff wave barriers include the study of four rows of $12 \mathrm{~m}$ deep lime-cement columns installed next to a track in Sweden [42]. Within the frame of the EU FP7 project RIVAS (Railway Induced Vibration Abatement Solutions) [44], a $55 \mathrm{~m}$ long and $7.5 \mathrm{~m}$ deep jet grouting wall was installed next to a track on a test site in Spain [43]. Both tests proved successful with a significant reduction of vibration already at low frequencies, but the performance decreases further away from the barriers.

In this paper, the vibration isolation efficiency of a sheet pile wall is investigated. At Furet, Sweden, a sheet pile wall with a length of $100 \mathrm{~m}$ has been installed next to the track $[45,46]$ in order to reduce train induced vibrations in several buildings close to the railway track. The sheet pile wall designed and constructed by Trafikverket was subjected to experimental and theoretical analysis within the frame of the RIVAS project [44]. The results of this analysis are presented in this paper. Whereas a large number of papers either focusses on numerical predictions of mitigation effectiveness or on technical construction 
aspects, the effectiveness of the sheet pile wall in Furet is investigated both with state-of-the-art 2.5D numerical predictions and in situ testing.

The outline of the paper is as follows. Section 2 introduces the test site in Sweden and addresses the determination of the dynamic soil characteristics. The sheet pile wall design and installation is discussed in section 3. The results of the measurement campaign are subsequently presented in section 4 . The experimental results are compared to results obtained by coupled FE-BE simulations in section 5 . Additional simulations are performed for the case of a homogeneous halfspace for better understanding of the wave impeding effects and for the case of an isotropic wall to study the influence of orthotropy. Conclusions are drawn in section 6 .

\section{Site description and characterization}

The site of Furet (figure 1) is located in the southwest of Sweden in the city of Halmstad, $700 \mathrm{~m}$ north of Halmstad station, along the West Coast Line between Göteborg and Lund. The wooden buildings in Furet have two to three floors and were mostly built around 1950 at the north-west side of the track along a distance of $750 \mathrm{~m}$. The track is a classical ballasted track.

(a)

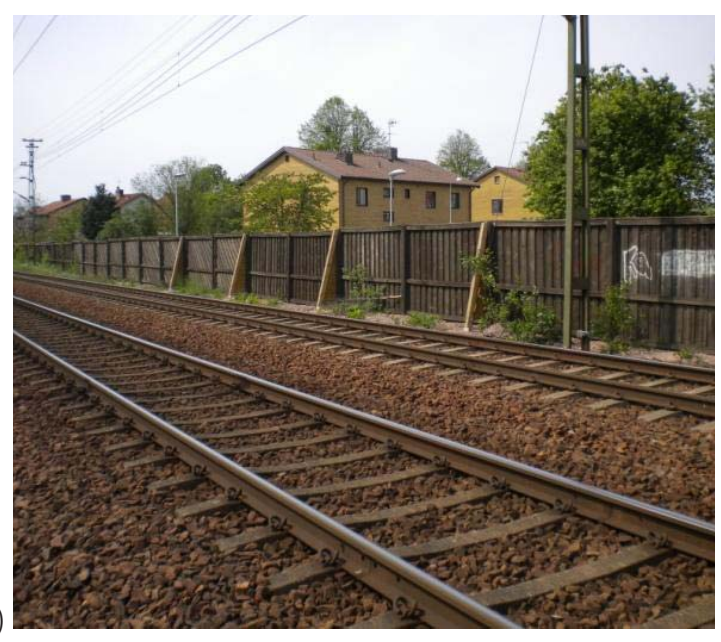

(b)

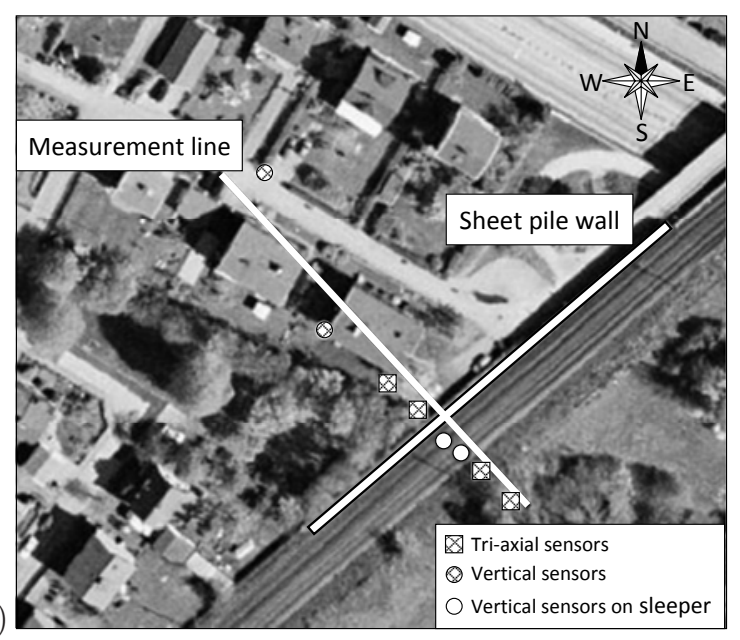

Figure 1: The site of Furet: (a) track, noise barrier and buildings close to the track, and (b) plan view with indication of the sheet pile wall and the setup for the measurement of the free field response due to train passages.

In 2002 a court decision stated that vibrations inside the buildings must be less than $1.0 \mathrm{~mm} / \mathrm{s}$ frequency weighted RMS at night (10 pm - 7 am). Measurements according to the Swedish Standard SS 4604861 [47] indicated that this threshold was exceeded in at least ten buildings in the south part of Furet with values ranging from 1.3 to $2.0 \mathrm{~mm} / \mathrm{s}$ frequency weighted RMS. The dominating frequency component of the indoor vibration was typically between 4 and $5 \mathrm{~Hz}$.

A first attempt to mitigate vibrations was undertaken in 2006. New sleepers with under sleeper pads were placed at the track closest to the buildings. At the same time, leveling of the track was carried out. 
These mitigation measures did not lead to a significant reduction of vibration levels in the houses. To further reduce the train induced vibrations at the site, a sheet pile wall was installed next to the track in 2011. Measurements after installation of the sheet pile wall showed sufficient reduction of vibration levels, except for a small three storey house with wooden structure at approximately $40 \mathrm{~m}$ from the track.

Geotechnical and geophysical tests have been carried out for the determination of the soil layering and the dynamic soil characteristics at the test site. Surveys, performed by the consulting company Tyréns in March and April 2011 at 4 locations in the area up to a depth of at least $18 \mathrm{~m}$, include cone penetration tests (CPT), seismic cone penetration tests (SCPT), standard piston sampling, sampling by Helical auger and weight sounding. The soil profile consists of a relatively firm layer of sand up to $2-3 \mathrm{~m}$ depth underlain by clayey silt up to a depth of $5-10 \mathrm{~m}$, underlain by silty clay. The silt has a density of $1850 \mathrm{~kg} / \mathrm{m}^{3}$ and the clay a density of $1710 \mathrm{~kg} / \mathrm{m}^{3}$. These densities are determined as average values from three samples per meter from one borehole. The CPT tests indicate an undrained shear strength of $20-35 \mathrm{kPa}$ up to $13 \mathrm{~m}$ depth and an undrained shear strength of $50-70 \mathrm{kPa}$ at larger depths.

The shear wave velocity $C_{\mathrm{s}}$ was determined by means of a multichannel analysis of surface waves (MASW) and SCPT test [48]. Two setups were used for the MASW test that was performed in August 2011 within the frame of the RIVAS project by the company Tyréns. The first setup employed 24 geophones in a straight line perpendicular to the track, equally spaced between $10 \mathrm{~m}$ and $56 \mathrm{~m}$ from the point of impact. In the second setup, 24 geophones were used in a straight line perpendicular to the track, equally spaced between $10 \mathrm{~m}$ and $33 \mathrm{~m}$ from the point of impact. Hammer impacts on an aluminum foundation were used as excitation. The MASW tests reveal a $2 \mathrm{~m}$ thick top layer with a shear wave velocity of about $160 \mathrm{~m} / \mathrm{s}$, followed by a $10 \mathrm{~m}$ thick layer with a shear wave velocity of $119 \mathrm{~m} / \mathrm{s}$ and an underlying halfspace with a shear wave velocity of about $200 \mathrm{~m} / \mathrm{s}$. The SCPT test indicates a shear wave velocity of $110 \mathrm{~m} / \mathrm{s}$ between 3 and $14 \mathrm{~m}$, and $150 \mathrm{~m} / \mathrm{s}$ between 15 and $18 \mathrm{~m}$. The results from the different in situ tests for the second layer are in good agreement. The MASW test shows a higher shear wave velocity velocity for the underlying halfspace, perhaps due to the presence of stiffer layers at larger depths.

Based on the results of the tests, a simplified horizontally layered soil model has been identified [48] with a shear wave velocity profile given in table 1 . An inverse layering is present at the site with a stiffer layer on top of a softer layer. The presence of the stiffer top layer impedes the determination of the dilatational wave velocity $C_{\mathrm{p}}$ from a seismic refraction test; the values for $C_{\mathrm{p}}$ are estimated from the results for $C_{\mathrm{s}}$ assuming a

\begin{tabular}{ccccccc}
\hline Layer & $\begin{array}{c}h \\
{[\mathrm{~m}]}\end{array}$ & $\begin{array}{c}C_{\mathrm{s}} \\
{[\mathrm{m} / \mathrm{s}]}\end{array}$ & $\begin{array}{c}C_{\mathrm{p}} \\
{[\mathrm{m} / \mathrm{s}]}\end{array}$ & $\begin{array}{c}\beta_{\mathrm{s}} \\
{[-]}\end{array}$ & $\begin{array}{c}\beta_{\mathrm{p}} \\
{[-]}\end{array}$ & $\begin{array}{c}\rho \\
{\left[\mathrm{kg} / \mathrm{m}^{3}\right]}\end{array}$ \\
\hline 1 & 2 & 154 & 375 & 0.025 & 0.025 & 1800 \\
2 & 10 & 119 & 290 & 0.025 & 0.025 & 1850 \\
3 & $\infty$ & 200 & 490 & 0.025 & 0.025 & 1710 \\
\hline
\end{tabular}

Table 1: Dynamic soil characteristics for the Furet site. 


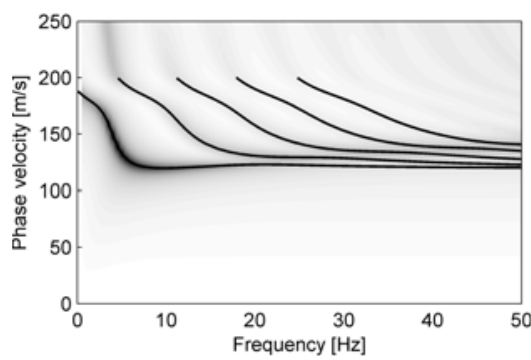

(a)

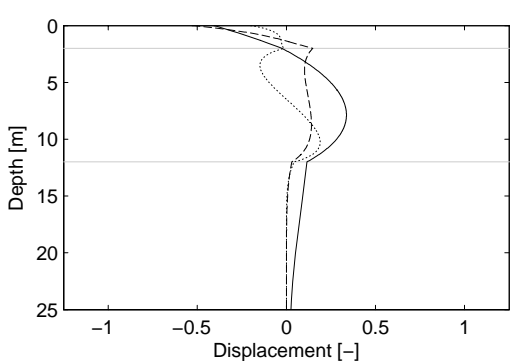

(b)

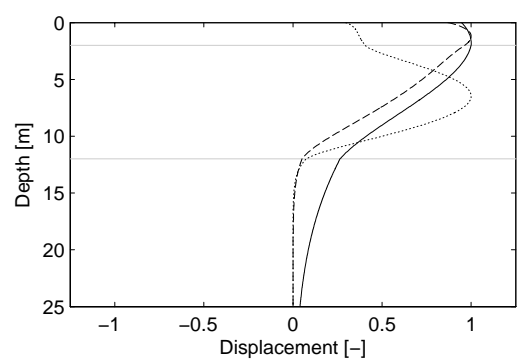

(c)

Figure 2: Rayleigh wave modes calculated for the Furet soil profile: (a) dispersion curves of the first five Rayleigh wave modes, and dimensionless (b) horizontal and (c) vertical component of the fundamental Rayleigh wave mode as a function of depth at $5 \mathrm{~Hz}$ (solid line), $15 \mathrm{~Hz}$ (dashed line) and $25 \mathrm{~Hz}$ (dotted line).

Poisson's ratio of 0.40. Table 1 provides a summary of the layer thickness $h$ and dynamic soil characteristics (shear wave velocity $C_{\mathrm{s}}$, dilatational wave velocity $C_{\mathrm{p}}$, density $\rho$, material damping ratios $\beta_{\mathrm{s}}$ and $\beta_{\mathrm{p}}$ in both deviatoric and volumetric deformation) for each layer. The material damping ratios are estimated values as the soil damping has not been determined experimentally.

Figure 2a shows the dispersion curve of the first five Rayleigh wave modes for the Furet soil profile of table 1, computed with the ElastoDynamics Toolbox (EDT) for MATLAB [49]. The phase velocity of the first (fundamental) Rayleigh wave mode varies strongly at low frequencies. At very low frequencies, the phase velocity is close to $180 \mathrm{~m} / \mathrm{s}$, corresponding to the phase velocity of Rayleigh waves in the underlying halfspace. Above $8 \mathrm{~Hz}$, it remains almost constant with a value around $120 \mathrm{~m} / \mathrm{s}$, corresponding to the Rayleigh wave velocity in the softer second layer. The cut-on frequencies of the four higher order Rayleigh waves are observed at $5,11,18$, and $25 \mathrm{~Hz}$. The grey area in the background of figure 2 a shows the frequencywavenumber spectrum of the vertical velocity at the free surface of the layered halfspace due to a vertical point load applied at the surface. The vertical velocity is dominated by the fundamental Rayleigh wave of the layered halfspace up to $20 \mathrm{~Hz}$. At higher frequencies, higher modes dominate the response because an inverse layering is present at the site [50]. Figures $2 \mathrm{~b}$ and $2 \mathrm{c}$ show the dimensionless horizontal and vertical component of the fundamental Rayleigh mode at 5,15 , and $25 \mathrm{~Hz}$. The curves are normalized by scaling the maximal vertical displacement to a unit value. Already at $5 \mathrm{~Hz}$, the motion is mainly limited to the top two layers, in agreement with the reduction of the phase velocity of the Rayleigh wave around $4-5 \mathrm{~Hz}$. At $15 \mathrm{~Hz}$, the motion in the top layer is more important than at $5 \mathrm{~Hz}$, whereas at $25 \mathrm{~Hz}$, the motion is concentrated in the second softer layer.

\section{Design and installation of the sheet pile wall}

Mitigation measures taken in 2006, including the installation of new sleepers with under sleeper pads at the track closest to the buildings and leveling of the tracks, were not successful, necessitating a further reduction of vibration levels in nearby houses. The highest vibration levels were measured at frequencies of 
$4-5 \mathrm{~Hz}$. Tests in Finland with sheet pile walls in soft soils have indicated a reduction up to $50 \%$ of vertical vibrations at low frequencies [51]. Therefore, it was decided to use a sheet pile wall as a vibration mitigation measure at the site.

The design and construction of the sheet pile wall were performed by Trafikverket prior to the RIVAS project. The efficiency of two alternative designs was assessed by means of a FLAC3D [52] analysis. In the first design, a sheet pile wall with a length of $100 \mathrm{~m}$ and a uniform depth of $13 \mathrm{~m}$ was considered. In the second design, the depth of the sheet piles is $12 \mathrm{~m}$ with every fourth pile extended to $18 \mathrm{~m}$. In both designs, the sheet pile wall cuts through the second softer layer. The second design was a compromise between good performance at low frequencies and cost, and has not been optimized with respect to alternating distance or depths. Originally, it was planned to use PU 12 profiles. The PU 12 profile was modeled as a solid element with $500 \mathrm{~mm}$ width and a Young's modulus of $5 \mathrm{GPa}$, disregarding orthotropy. The analysis indicated a reduction of vibration levels of 25 to $40 \%$ behind the wall and an increase of 20 to $50 \%$ in front of the wall. Comparing both designs, the sheet pile wall with alternating depths had a significantly better vibration isolation efficiency in the targeted low frequency range of $4-5 \mathrm{~Hz}$. Therefore, the second design was chosen for the sheet pile wall (figure 3a). The sheet piles installed are VL 603-K profiles (figure 3b). The properties of the VL $603-\mathrm{K}$ profile are given in table 2. The sheet pile wall is built at the north-west side of the track and starts at the bridge end, which is visible in the upper right corner of figure $1 \mathrm{~b}$. The total length of the sheet pile wall is $100 \mathrm{~m}$. The wall is interrupted at four places to allow for the passage of pipes and cables. The distance from the center of the nearest track to the center of the sheet pile wall is approximately $5.6 \mathrm{~m}$. The installation of the sheet pile wall is shown in figure 4. A small rig was used to push down each sheet pile for the first $10 \mathrm{~m}$ (respectively $16 \mathrm{~m}$ ) of the total $12 \mathrm{~m}$ (respectively $18 \mathrm{~m}$ ). Adjacent sheet piles were welded together over the top $0.3 \mathrm{~m}$ (figure $4 \mathrm{~b}$ ). A large rig was finally used to push down three sheet piles at a time for the last $2 \mathrm{~m}$. After installation, the sheet pile wall was covered with about $0.5 \mathrm{~m}$ of soil. During sheet pile installation, the track geometry was controlled once a day and vibration levels were monitored in all nearby buildings. The measured vibration levels were lower than the limit values for damage to buildings. Damage was also not observed during visual inspections of the nearest buildings before and after installation of the sheet pile wall.

\begin{tabular}{cccc}
\hline $\begin{array}{c}\text { Mass } m_{\mathrm{w}} \\
{\left[\mathrm{kg} / \mathrm{m}^{2}\right]}\end{array}$ & $\begin{array}{c}\text { Sectional area } A_{\mathrm{w}} \\
{\left[\mathrm{cm}^{2} / \mathrm{m}\right]}\end{array}$ & $\begin{array}{c}\text { Moment of inertia } I_{\mathrm{w}} \\
{\left[\mathrm{cm}^{4} / \mathrm{m}\right]}\end{array}$ & $\begin{array}{c}\text { Width } t_{\mathrm{w}} \\
{[\mathrm{m}]}\end{array}$ \\
\hline 113.5 & 144.8 & 18900 & 0.310 \\
\hline
\end{tabular}

Table 2: Geometrical properties of the sheet pile wall (VL 603-K profile). 


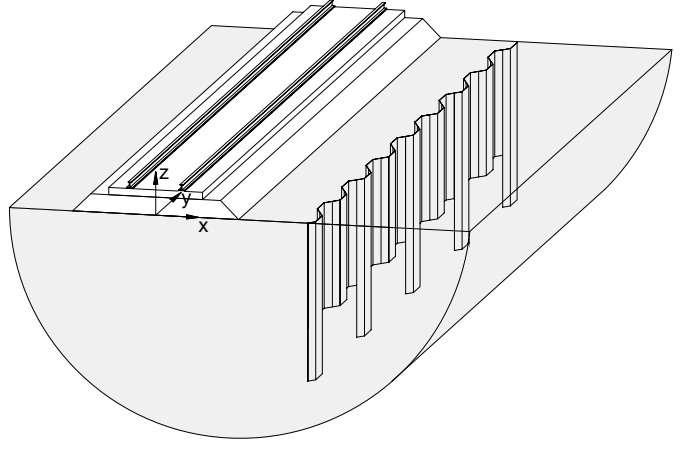

(a)

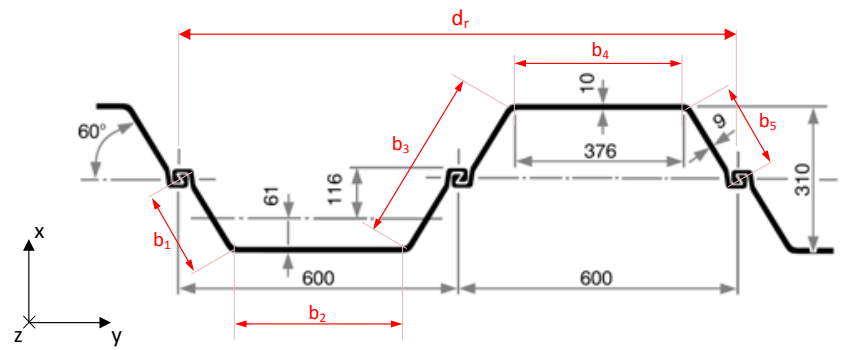

(b)

Figure 3: (a) Design of the sheet pile wall and (b) cross section of the VL 603-K profiles.

(a)

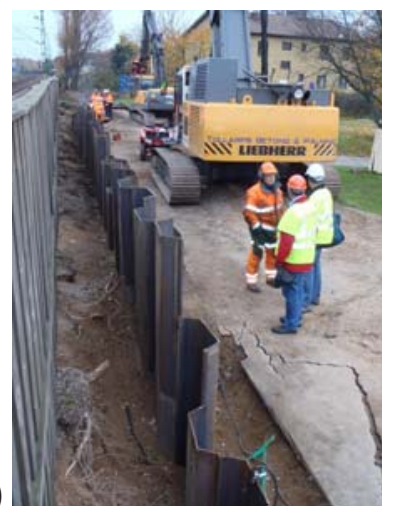

(b)

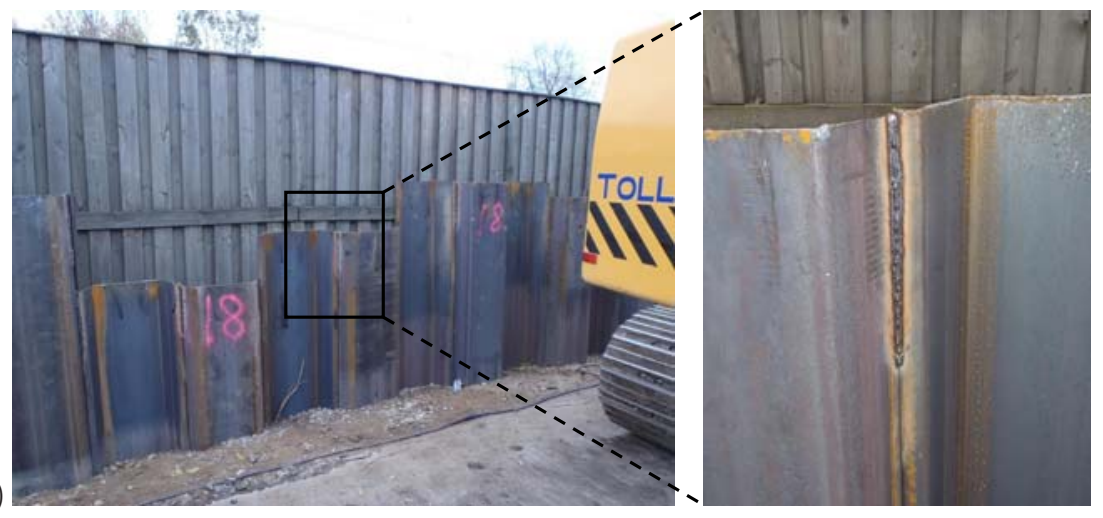

Figure 4: Installation of the sheet pile wall: (a) general view after installation of sheet piles up to a depth of 10/16 $\mathrm{m}$ with the small rig, (b) welding of the top $0.3 \mathrm{~m}$. 


\section{Experimental evaluation of the vibration mitigation performance}

The efficacy of the sheet pile wall is evaluated by comparing the vibration levels due to train passages before and after installation of the sheet pile wall. Measurement campaigns have been carried out within the frame of the RIVAS project by Trafikverket in October and December 2011, which lasted an entire week to include all types of traffic and to cover differences between week days and weekend. The free field vertical vibration velocities were measured along a line perpendicular to the track, close to the middle of the sheet pile wall (figure 1b). Geophones were placed at 8, 16, 32, and $64 \mathrm{~m}$ from the center of the track. Geophones were also placed at 8 and $16 \mathrm{~m}$ at the opposite side of the track to verify a possible increase in vibration levels. Two geophones were placed on the sleepers for the detection of the train speed.

A comparison of the maximum vertical vibration levels recorded during the measurements indicates a significant reduction in vertical vibration level behind the sheet pile wall at 8,16 , and $32 \mathrm{~m}$ from the track center. The efficacy is higher closer to the wall where the maximum vibration level is reduced by about $50 \%$. At $32 \mathrm{~m}$ the maximum values are reduced by about $30 \%$. At $64 \mathrm{~m}$ from the track center, no reduction in maximum vibration level is observed. The measurements at the other side of the track show no increase in vertical vibration level.

The vertical insertion loss $\mathrm{IL}_{z}(f)$ is determined from the mean vibration level $\bar{L}_{\mathrm{v}}^{\text {before }}(f)$ before installation of the wall and the mean vibration level $\bar{L}_{\mathrm{v}}^{\text {after }}(f)$ after installation of the wall [53]:

$$
\mathrm{IL}_{z}(f)=\bar{L}_{\mathrm{v}}^{\text {before }}(f)-\bar{L}_{\mathrm{v}}^{\text {after }}(f) .
$$

The one-third octave band spectra of the vibration velocity for each train passage are determined according to the procedure described in [53]. In order to reduce uncertainties, the RIVAS measurement protocol [53] recommends to combine equation (1) with a comparison of vibration levels obtained at adjacent track sections with and without measure. As measurement results on an adjacent reference site are not available, however, a correction for temporal variations of track, train and soil conditions as performed in [43] is not possible. It is important that passages of similar trains running at similar speed are compared before and after installation of the sheet pile wall. The trains identified during the measurements are mainly X31 passenger trains and freight trains [54]. The X31 passenger train is an electric multiple unit train consisting of three cars with a total length of $79 \mathrm{~m}$. Three categories of trains are selected from all recorded train passages for the determination of the insertion loss. The X31 passenger trains are divided in two categories according to train speed. The first category consists of trains with an average speed of $77 \mathrm{~km} / \mathrm{h} \pm 5 \%$ before installation and $72 \mathrm{~km} / \mathrm{h} \pm 5 \%$ after installation, respectively. The second category consists of trains with an average speed of $81 \mathrm{~km} / \mathrm{h} \pm 5 \%$ before and after installation. The third category consists of freight trains

with an average speed of $63 \mathrm{~km} / \mathrm{h} \pm 5 \%$. Table 3 lists the number of trains used in the determination of insertion loss for the three train categories. Not all measurement results are available for all geophones, 
probably due to cable connection problems.

Although train passages of the same type at approximately the same speed are considered in each category, a considerable variation is observed in the frequency spectra of the measured vibration levels. This variability is caused by differences in train properties (train speed, wheel unevenness) and the variation of track characteristics (rail unevenness, ballast stiffness) in space and time. The standard deviation of the insertion loss is estimated as $\sigma_{\mathrm{IL}_{z}}(f)=\sqrt{\sigma_{L_{\mathrm{v}}^{\text {before }}}^{2}(f)+\sigma_{L_{\mathrm{v}}}^{2} \text { after }(f)}$, with $\sigma_{L_{\mathrm{v}}^{\text {before }}}^{2}(f)$ and $\sigma_{L_{\mathrm{v}}^{\text {after }}}^{2}(f)$ the sample variance of the vibration levels before and after installation, respectively. The $95 \%$ confidence interval of the mean value is estimated as $\mathrm{IL}_{z}(f) \pm \alpha \frac{\sigma_{\mathrm{IL}_{z}(f)}}{\sqrt{n}}$, with $n$ the number of train passages and $\alpha$ the $5 \%$ value of a Student's $t$-distribution with $n-1$ degrees of freedom [55]. The lowest number $n$ is used when the number of train passages used in the determination of $\bar{L}_{\mathrm{v}}^{\text {before }}(f)$ and $\bar{L}_{\mathrm{v}}^{\text {after }}(f)$ is different.

\begin{tabular}{|c|c|c|c|c|c|c|c|}
\hline \multirow[t]{2}{*}{ Category } & \multirow[t]{2}{*}{ Train type } & & \multirow{2}{*}{$\begin{array}{l}\text { Speed } \\
{[\mathrm{km} / \mathrm{h}]}\end{array}$} & \multicolumn{4}{|c|}{ Receiver distance } \\
\hline & & & & $8 \mathrm{~m}$ & $16 \mathrm{~m}$ & $32 \mathrm{~m}$ & $64 \mathrm{~m}$ \\
\hline \multirow[t]{2}{*}{1} & \multirow[t]{2}{*}{ X31 passenger trains } & before & $77 \pm 5 \%$ & 10 & 10 & $T$ & $T$ \\
\hline & & after & $72 \pm 5 \%$ & 10 & 10 & $T$ & $T$ \\
\hline \multirow[t]{2}{*}{2} & \multirow[t]{2}{*}{ X31 passenger trains } & before & $81 \pm 5 \%$ & 9 & 9 & 1 & 9 \\
\hline & & after & $81 \pm 5 \%$ & 6 & 7 & $T$ & 7 \\
\hline \multirow[t]{2}{*}{3} & \multirow[t]{2}{*}{ Freight trains } & before & $63 \pm 5 \%$ & 5 & 5 & 5 & 5 \\
\hline & & after & $63 \pm 5 \%$ & 4 & 4 & 4 & 4 \\
\hline
\end{tabular}

Table 3: Number of trains used in the experimental determination of insertion loss for the three train categories.

Figure 5 shows the measured vibration velocity levels $L_{v}$ for the X31 passenger trains with average speed of $77 \mathrm{~km} / \mathrm{h}$ before (black) and $72 \mathrm{~km} / \mathrm{h}$ after (red) construction of the sheet pile wall. The arithmetically averaged vibration velocity levels $\bar{L}_{v}$ and the average background velocity level are superimposed on figure 5. A peak of $L_{v}$ near $30-40 \mathrm{~Hz}$ is clearly observed at 8 and $16 \mathrm{~m}$ from the track which may be associated with resonance of the unsprung mass on the track stiffness. The peak is more pronounced after construction of the sheet pile wall. The resulting insertion loss and $95 \%$ confidence interval of the mean value obtained from these train passages are shown in figure 6 . At $8 \mathrm{~m}$, which is located $2.4 \mathrm{~m}$ behind the wall, the sheet pile wall reduces vibrations from $4 \mathrm{~Hz}$ upwards. At $16 \mathrm{~m}$ from the track, the reduction in vibration levels starts at $8 \mathrm{~Hz}$. Up to a frequency of $16-20 \mathrm{~Hz}$, the measured insertion loss generally increases with frequency and decreases with distance from the sheet pile wall. The negative insertion loss around $31.5 \mathrm{~Hz}$ and at higher frequencies as found from these measured train passages are not observed in any other measurements or predictions for sheet pile walls and are therefore believed to have other causes.

Figure 7 shows the measured vibration velocity levels $L_{v}$ for the X31 passenger trains with average speed of $81 \mathrm{~km} / \mathrm{h}$. The velocity levels still exhibit a peak around $30-40 \mathrm{~Hz}$ but this peak is less pronounced than for the passenger trains with average speed of $77 \mathrm{~km} / \mathrm{h}$ and $72 \mathrm{~km} / \mathrm{h}$. Furthermore, it can be observed that the vibration velocity level decreases with increasing distance from the track; especially the high frequencies 


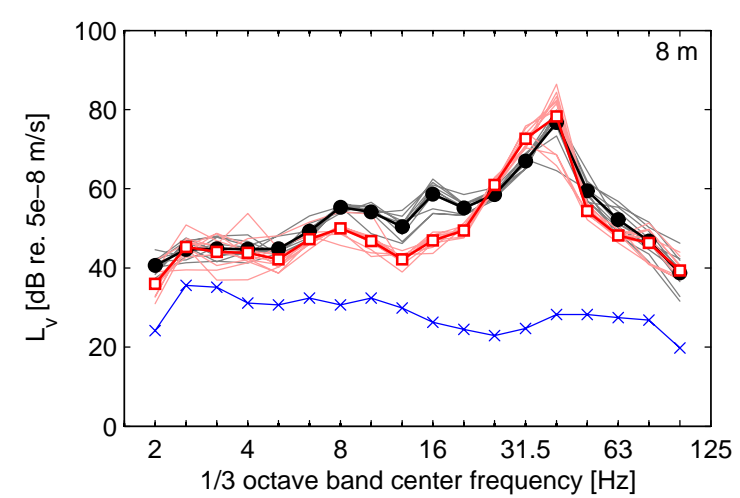

(a)

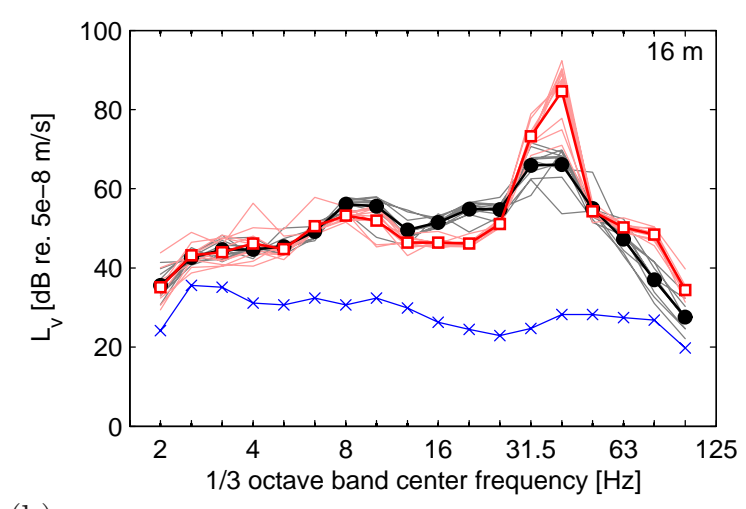

(b)

Figure 5: Measured vibration velocity level $L_{v}$ in one-third octave bands at (a) $8 \mathrm{~m}$ and (b) $16 \mathrm{~m}$ during the passage of X31 passenger trains at an average speed of $77 \mathrm{~km} / \mathrm{h}$ before (black) and $72 \mathrm{~km} / \mathrm{h}$ after (red) installation of the sheet pile wall. The averaged vibration velocity level before $(\bullet)$ and after $(\square)$ installation, and the average background vibration level $(\times)$ are superimposed.

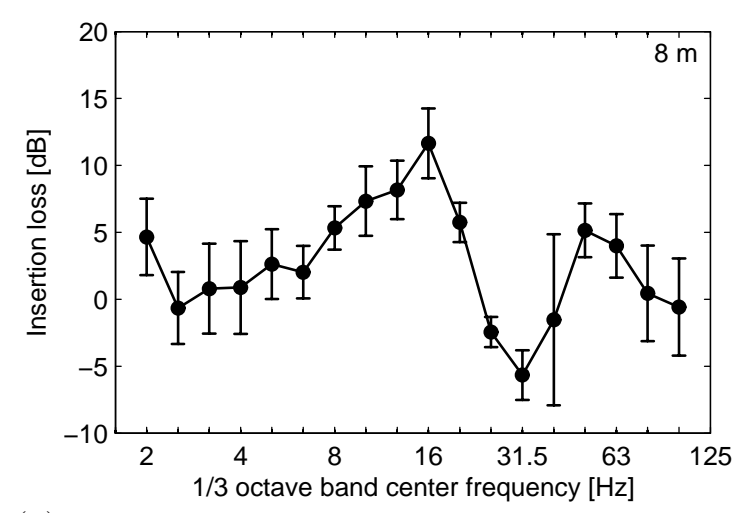

(a)

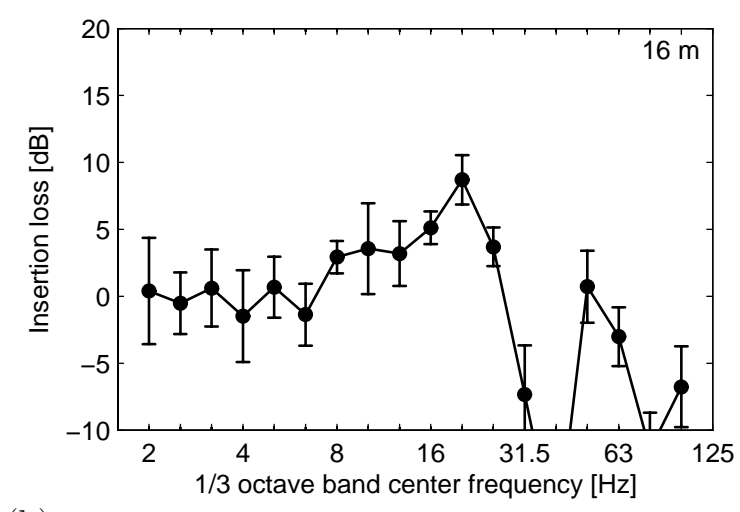

(b)

Figure 6: Measured insertion loss $\mathrm{IL}_{z}$ in one-third octave bands at (a) $8 \mathrm{~m}$ and (b) $16 \mathrm{~m}$ for X31 passenger trains at an average speed of $77 \mathrm{~km} / \mathrm{h}$ (before installation) and $72 \mathrm{~km} / \mathrm{h}$ (after installation). The $95 \%$ confidence interval estimates of the mean value are indicated by error bars.

are attenuated due to material damping in the soil. The velocity levels at $64 \mathrm{~m}$ are relatively low and disturbed by background noise at high frequencies. The corresponding insertion loss is shown in figure 8 . The uncertainty is larger than for category 1 because a lower number of train passages are considered in the determination of the insertion loss. Positive insertion loss values are found above $4 \mathrm{~Hz}$ as in the previous results. In the frequency range $6-31.5 \mathrm{~Hz}$, the insertion loss generally increases with frequency. The highest reduction is measured immediately behind the sheet pile wall while no reduction is observed at $64 \mathrm{~m}$. Above $31.5 \mathrm{~Hz}$, the insertion loss again decreases but generally remains positive.

Figure 9 shows the measured vibration velocity levels $L_{v}$ for the freight trains with average speed of $63 \mathrm{~km} / \mathrm{h}$. Higher vibration levels are observed in comparison to the passenger trains, in particular at low frequencies. At 8 and $16 \mathrm{~m}$, the vibration level shows a broad peak around $3-10 \mathrm{~Hz}$ and a peak around $30-40 \mathrm{~Hz}$. At larger distances, the vibration levels at high frequencies are strongly attenuated and the 


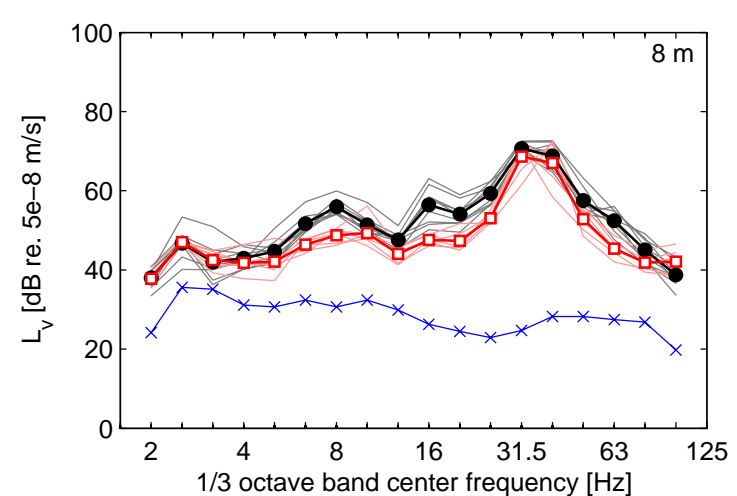

(a)

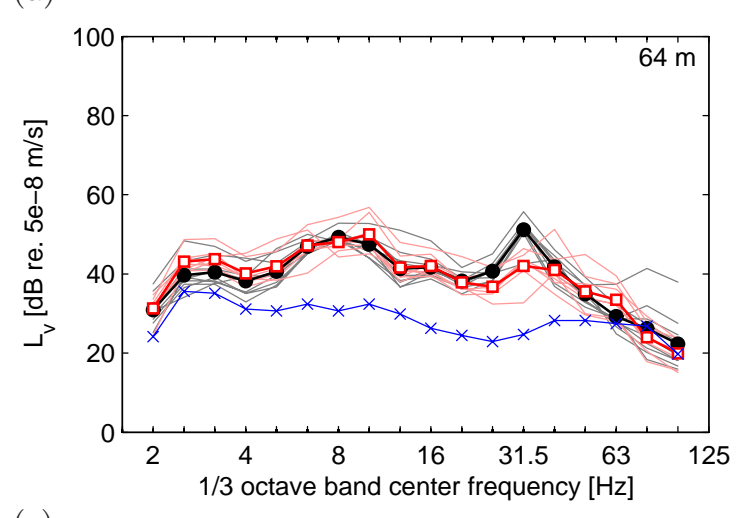

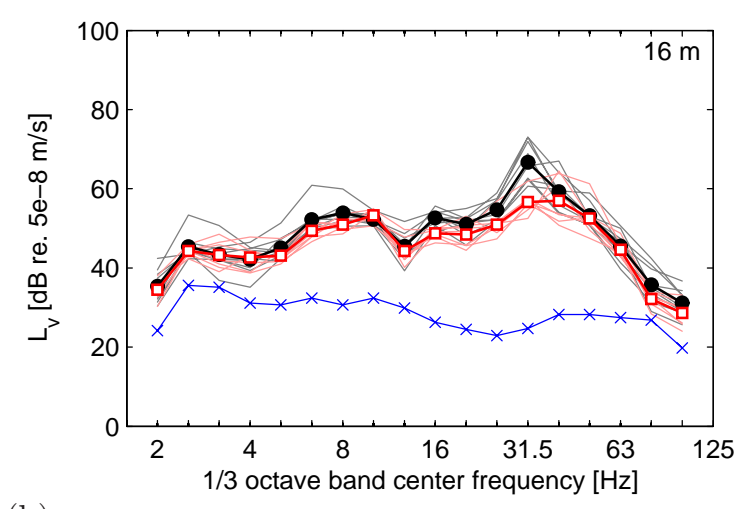

(b)

(c)

Figure 7: Measured vibration velocity level $L_{v}$ in one-third octave bands at (a) $8 \mathrm{~m}$, (b) $16 \mathrm{~m}$, and (c) $64 \mathrm{~m}$ during the passage of X31 passenger trains at an average speed of $81 \mathrm{~km} / \mathrm{h}$ before (black) and after (red) installation of the sheet pile wall. The averaged vibration velocity level before $(\bullet)$ and after $(\square)$ installation, and the average background vibration level $(\times)$ are superimposed.

maximum vibration levels are observed in the frequency range $3-10 \mathrm{~Hz}$. The insertion loss for these freight trains is shown in figure 10. High insertion loss values of up to $5-10 \mathrm{~dB}$ are obtained in a broad frequency range, already at very low frequencies. Again, the largest reduction is observed at $8 \mathrm{~m}$. These results should be interpreted with care, however, as large uncertainty is caused by the limited number of train passages and the relatively large scatter between the individual pass-by spectra.

It can be concluded from the measurement results for the three train categories that, as a general trend, positive insertion loss is found from $4 \mathrm{~Hz}$ upwards. Up till $20-30 \mathrm{~Hz}$, the measured insertion loss generally increases with frequency. Finally, the efficacy of the sheet pile wall generally decreases with distance from the sheet pile wall. The variability of the insertion loss results is on average $\pm 3 \mathrm{~dB}$ for the passenger trains and $\pm 10 \mathrm{~dB}$ for the freight trains. This variability is mainly due to differences in wheel unevenness, rail unevenness and ballast stiffness before and after installation. For freight trains, differences in train characteristics can be another cause for the very large variability. These differences could be corrected for by combining the measurements before and after with a comparison of vibration levels obtained at adjacent track sections with and without measure, as recommended in the RIVAS measurement protocol [53] and 


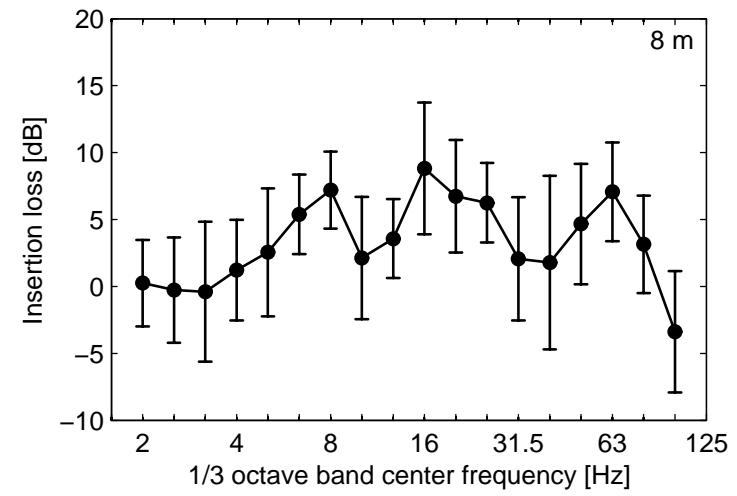

(a)

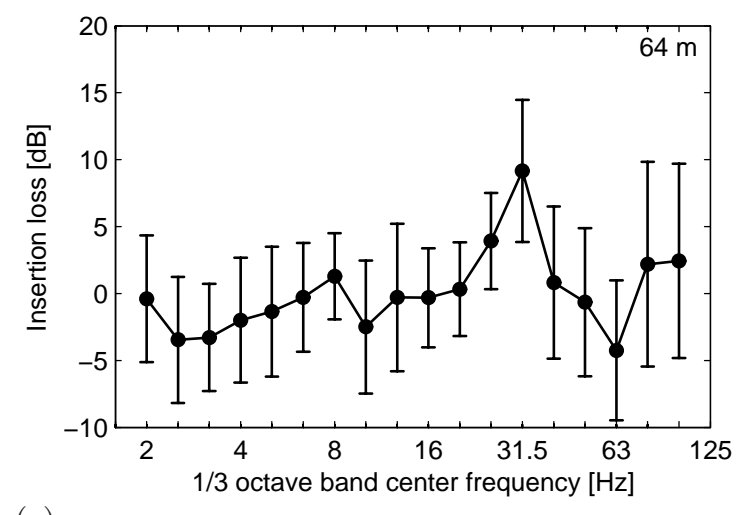

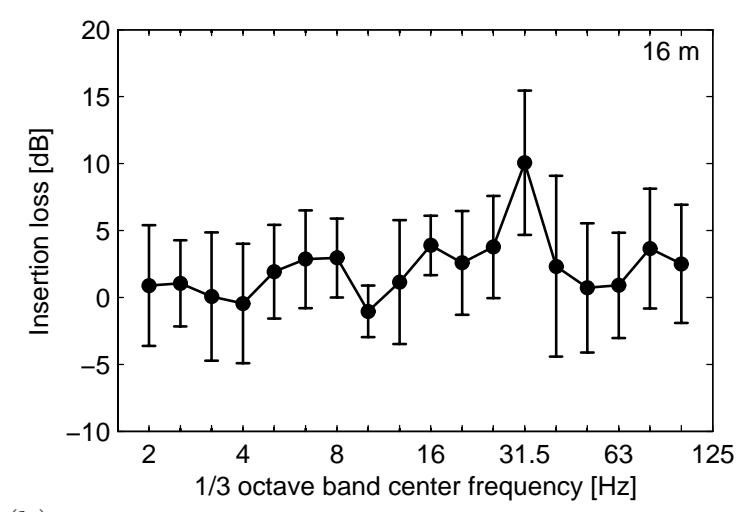

(b)

(c)

Figure 8: Measured insertion loss $\mathrm{IL}_{z}$ in one-third octave bands at (a) $8 \mathrm{~m}$, (b) $16 \mathrm{~m}$, and (c) $64 \mathrm{~m}$ for X31 passenger trains at an average speed of $81 \mathrm{~km} / \mathrm{h}$. The $95 \%$ confidence interval estimates of the mean value are indicated by error bars.

performed in [43]. Furthermore, the uncertainty can be reduced by increasing the number of train passages in each train category. 


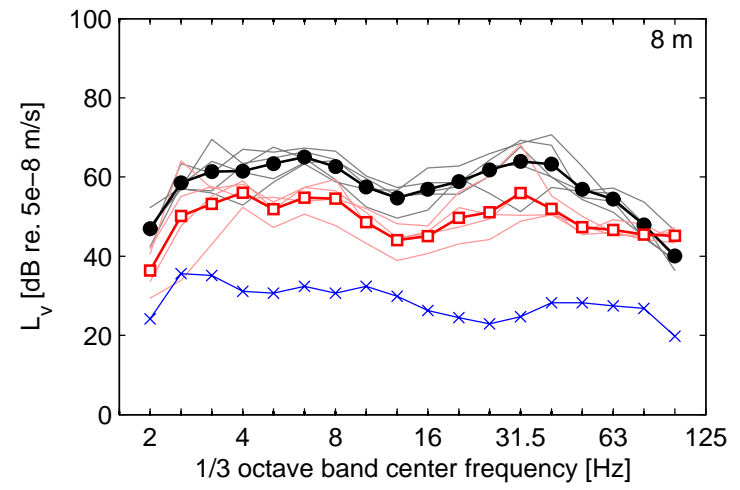

(a)

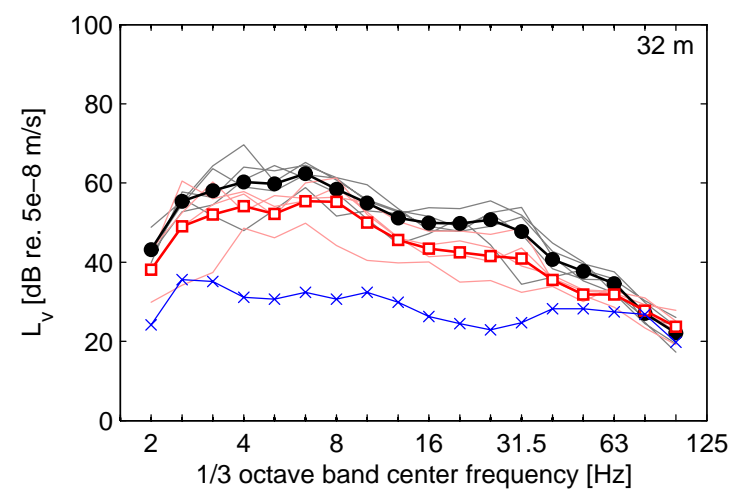

(c)

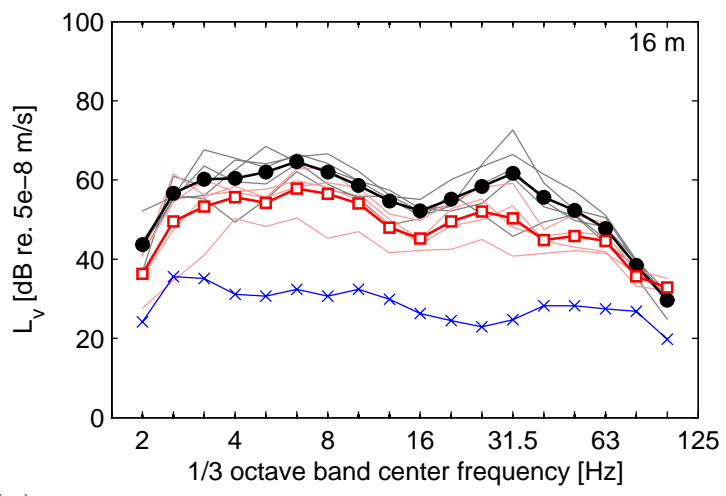

(b)

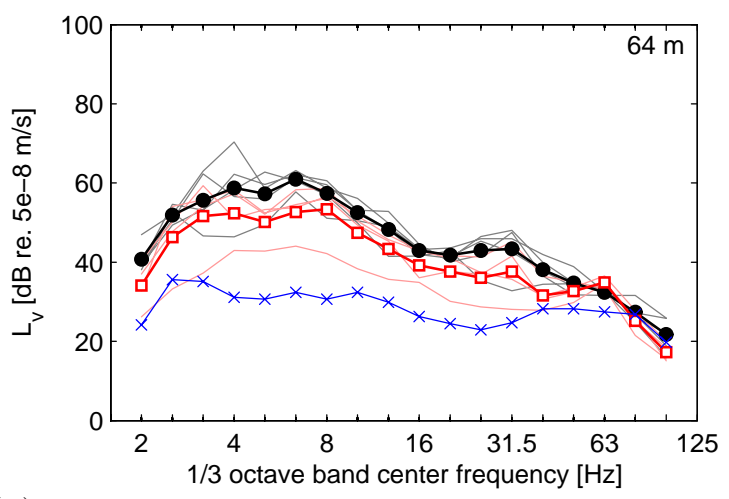

(d)

Figure 9: Measured vibration velocity level $L_{v}$ in one-third octave bands at (a) $8 \mathrm{~m}$, (b) $16 \mathrm{~m}$, (c) $32 \mathrm{~m}$, and (d) $64 \mathrm{~m}$ during the passage of freight trains at an average speed of $63 \mathrm{~km} / \mathrm{h}$ before (black) and after (red) installation of the sheet pile wall. The averaged vibration velocity level before $(\bullet)$ and after $(\square)$ installation, and the average background vibration level $(\times)$ are superimposed. 


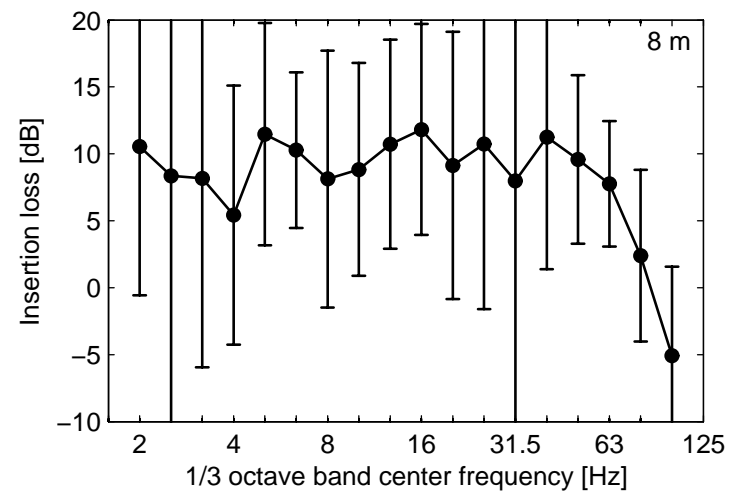

(a)

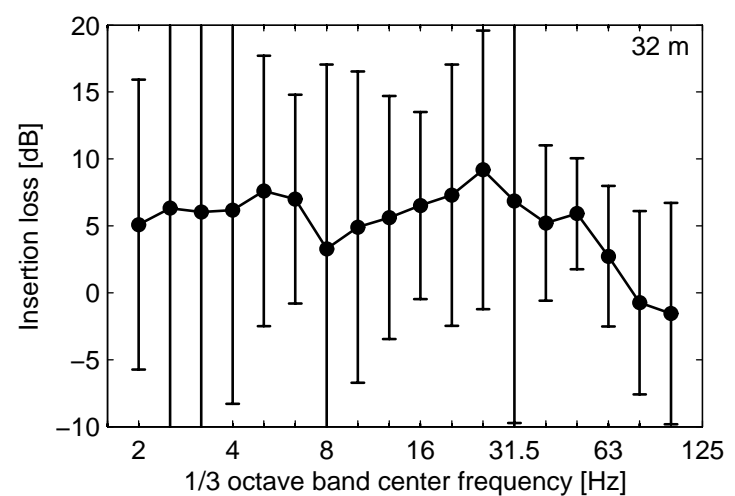

(c)

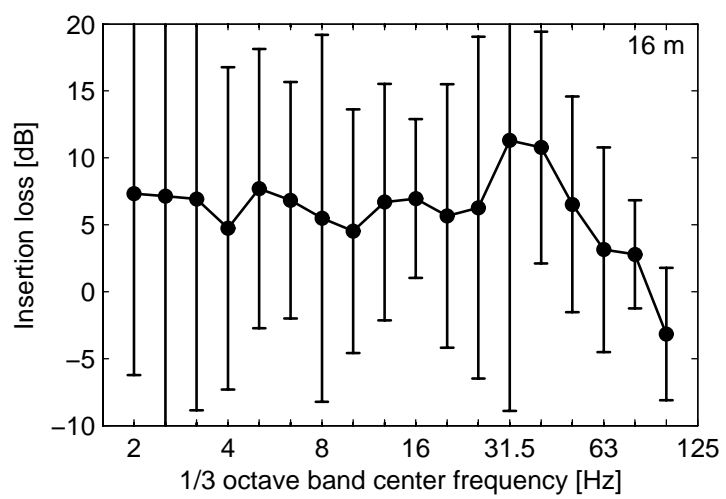

(b)

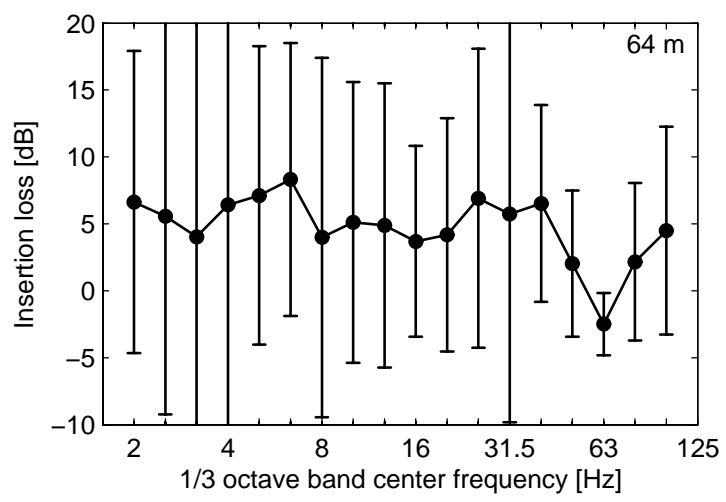

(d)

Figure 10: Measured insertion loss $\mathrm{IL}_{z}$ in one-third octave bands at (a) $8 \mathrm{~m}$, (b) $16 \mathrm{~m}$, (c) $32 \mathrm{~m}$, and (d) $64 \mathrm{~m}$ for freight trains at an average speed of $63 \mathrm{~km} / \mathrm{h}$. The $95 \%$ confidence interval estimates of the mean value are indicated by error bars. 


\section{Numerical analysis of the vibration mitigation performance}

\subsection{Methodology}

In this section, the efficacy of the sheet pile wall is studied by means of numerical simulations, taking into account the 3D wave field in the soil and the dynamic interaction between the soil and the wall. The wall is assumed to be infinitely long with a uniform cross section, so that a computationally efficient 2.5D method can be applied. The origin of the Cartesian frame of reference is placed at the soil's surface at the centre of the track (figure 3). The $x$-axis is in the direction perpendicular to the track, the $y$-axis is parallel to the track and the $z$-axis is vertical. The longitudinal coordinate $y$ is transformed to the wavenumber $k_{y}$ by means of a forward Fourier transform. A dynamic soil-structure interaction problem with 2D geometry is solved for each frequency $\omega$ and wavenumber $k_{y}$ by means of a coupled FE-BE methodology and the 3D solution is obtained by an inverse Fourier transformation with respect to the wavenumber $k_{y}$. The reader is referred to the literature for a comprehensive overview of this methodology [56].

First, the performance of a $12 \mathrm{~m}$ deep sheet pile wall, installed in a homogeneous halfspace, is investigated. The dynamic soil characteristics corresponding to the underlying halfspace at the site in Furet (table 1) are used for the homogeneous halfspace. In the FLAC3D analysis used for the design of the sheet pile wall, an equivalent isotropic plate model was adopted. For the sheet pile wall (figure 3), the bending stiffness around the $y-y$ axis (perpendicular to the profiles) is much larger than the bending stiffness around the $z-z$ axis (along the profiles). It is therefore investigated how disregarding the orthotropic behaviour of the sheet pile wall affects the numerical results.

Second, the efficacy of the sheet pile wall installed at the site in Furet is analysed. The actual sheet piles have a depth of $12 \mathrm{~m}$, with every fourth sheet pile extended to $18 \mathrm{~m}$. Since the use of a $2.5 \mathrm{D}$ model requires assuming a uniform geometry of the sheet pile wall along its longitudinal axis, separate calculations are made for depths of $12 \mathrm{~m}$ and $18 \mathrm{~m}$. The predicted insertion loss is compared with the measured values of section 4. Because no information is available about the track unevenness at the site in Furet, which determines the dynamic axle loads, a comparison of measurements and predictions in terms of the vibration velocity levels $L_{v}$ will not be pursued.

To reduce the calculation time, the presence of the track is disregarded in the model. A preliminary comparison has shown that the track has limited influence on the predicted insertion loss of stiff wave barriers, in particular at larger distances from the track [57]. A simplified procedure is adopted to compute the insertion loss for a train passage. Previous studies have shown that the stationary part of the free field response is well approximated by assuming the dynamic axle loads to be applied at fixed positions [58]. A sequence of fixed, incoherent point forces (referred to as a train load in the following) is therefore applied directly at the soil's surface at a distance $d=5.60 \mathrm{~m}$ from the sheet pile wall, corresponding to the distance from the center of the nearest track to the sheet pile wall. The train load consists of 12 uncorrelated unit 
point forces applied at the soil's surface at the axle positions of a $79 \mathrm{~m}$ long three car X31 passenger train, when the train is centred at $y=0$. Each car is supported by two bogies. The car length is $26.3 \mathrm{~m}$ and the bogie distance is $19 \mathrm{~m}$. The axle distance is $2.7 \mathrm{~m}$. The predicted insertion loss for the longer freight trains is very similar and therefore not shown here.

In the frequency range of interest, the bending wavelength $\lambda_{\mathrm{b} y}$ in the longitudinal direction in the sheet pile wall is much larger than the profile spacing $d_{\mathrm{r}}=1200 \mathrm{~mm}$ (figure $3 \mathrm{~b}$ ) of the sheet pile wall. The profiling of the plate can thus be disregarded and the sheet pile wall is modelled as an equivalent orthotropic plate. The thickness $\bar{t}$, mass density $\bar{\rho}$, Young's moduli $\bar{E}_{y}$ and $\bar{E}_{z}$, shear modulus $\bar{\mu}_{y z}$ and Poisson's ratios $\bar{\nu}_{y z}$ and $\bar{\nu}_{z y}$ of the equivalent orthotropic plate are chosen such that the plate has approximately the same mass, axial and bending stiffness as the VL $603-\mathrm{K}$ profile. The axial stiffness of the plate in the $z$-direction can be determined from the characteristics of the VL 603-K profile (table 2):

$$
\frac{\bar{E}_{z} \bar{t}}{1-\bar{\nu}_{y z} \bar{\nu}_{z y}}=E_{\mathrm{s}} A_{\mathrm{w}}=3.041 \times 10^{9} \mathrm{~N} / \mathrm{m}
$$

with $E_{\mathrm{s}}=210 \mathrm{GPa}$ the Young's modulus of steel. Bending wave propagation in an orthotropic plate is governed by the following partial differential equation [59]:

$$
\bar{B}_{\mathrm{p} y} \frac{\partial u_{x}^{4}}{\partial y^{4}}+2 \bar{B}_{\mathrm{p} y z} \frac{\partial u_{x}^{4}}{\partial y^{2} \partial z^{2}}+\bar{B}_{\mathrm{p} z} \frac{\partial u_{x}^{4}}{\partial z^{4}}-\omega^{2} \bar{\rho} \bar{t} u_{x}=0,
$$

where $u_{x}$ is the transverse displacement, $\bar{B}_{\mathrm{p} y}$ and $\bar{B}_{\mathrm{p} z}$ are the plate bending stiffness in the longitudinal $y$ direction and the vertical $z$-direction, respectively, and $\bar{B}_{\mathrm{p} y z}$ accounts for the cross-contractional and shear stiffness. The vertical bending stiffness $\bar{B}_{\mathrm{p} z}$ for bending around the $y$-axis can be determined from the characteristics of the VL 603-K profile (table 2):

$$
\bar{B}_{\mathrm{p} z}=\frac{\bar{E}_{z} \bar{t}^{3}}{12\left(1-\bar{\nu}_{y z} \bar{\nu}_{z y}\right)}=E_{\mathrm{s}} I_{\mathrm{w}}=3.97 \times 10^{7} \mathrm{Nm}^{2} / \mathrm{m}
$$

The longitudinal bending stiffness $\bar{B}_{\mathrm{p} y}$ for bending around the $z$-axis is approximately the same as for a plate with constant thickness, taking into account the effective increase in width due to the profiling [59]:

$$
\bar{B}_{\mathrm{p} y}=\frac{\bar{E}_{y} \bar{t}^{3}}{12\left(1-\bar{\nu}_{y z} \bar{\nu}_{z y}\right)}=\frac{E_{\mathrm{s}} h^{3}}{12\left(1-\nu_{\mathrm{s}}^{2}\right)} \frac{d_{\mathrm{r}}}{\sum b_{n}}=1.27 \times 10^{4} \mathrm{Nm}^{2} / \mathrm{m}
$$

with $\nu_{\mathrm{s}}=0.30$ the Poisson's ratio of steel, $h=9 \mathrm{~mm}$ the minimal thickness of the steel plate and $\sum b_{n}=$ $1320 \mathrm{~mm}$ the total profile length along $d_{\mathrm{r}}=1200 \mathrm{~mm}$ (figure $3 \mathrm{~b}$ ). Solving equations (2) and (4) yields $\bar{t}=0.396 \mathrm{~m}$ and $\bar{E}_{z} /\left(1-\bar{\nu}_{z y} \bar{\nu}_{y z}\right)=7.68 \mathrm{GPa}$. Due to the profiling of the sheet pile wall, the Poisson's ratios $\bar{\nu}_{y z}$ and $\bar{\nu}_{z y}$ can be assumed zero, resulting in a Young's modulus $\bar{E}_{z}=7.68 \mathrm{GPa}$. Solving equation (5) for the longitudinal Young's modulus yields a value $\bar{E}_{y}=2.47 \mathrm{MPa}$, which is approximately 3100 times smaller 
than $\bar{E}_{z} . \bar{B}_{\mathrm{p} y z}$ is determined by the cross-contractional and shear stiffness [59]:

$$
\bar{B}_{\mathrm{p} y z}=\frac{\bar{\nu}_{y z} \bar{E}_{z} \bar{t}^{3}}{12\left(1-\bar{\nu}_{y z} \bar{\nu}_{z y}\right)}+\frac{2 \bar{\mu}_{y z} \bar{t}^{3}}{12}
$$

and is taken equal to the geometric mean of the bending stiffness in the two orthogonal directions [59]:

$$
\bar{B}_{\mathrm{p} y z}=\sqrt{\bar{B}_{\mathrm{p} y} \bar{B}_{\mathrm{p} z}}
$$

Combining equations (6) and (7) and using $\bar{\nu}_{y z}=\bar{\nu}_{z y}=0$, the shear modulus of the equivalent orthotropic plate is given by:

$$
\bar{\mu}_{y z}=\frac{\sqrt{\bar{E}_{y} \bar{E}_{z}}}{2}=6.89 \times 10^{7} \mathrm{~N} / \mathrm{m}^{2} .
$$

For the mass density $\bar{\rho}$, a value of $286.6 \mathrm{~kg} / \mathrm{m}^{3}$ is chosen such that the equivalent plate has the same mass as the VL $603-\mathrm{K}$ profile:

$$
\bar{\rho} \bar{t}=m_{\mathrm{w}}=113.5 \mathrm{~kg} / \mathrm{m}^{2} .
$$

To investigate the importance of the orthotropic behaviour of the sheet pile wall, an isotropic plate model is also adopted, where the bending stiffness in the longitudinal and vertical direction are taken equal:

$$
\frac{\bar{E}_{y} \bar{t}^{3}}{12\left(1-\bar{\nu}_{y z} \bar{\nu}_{z y}\right)}=\frac{\bar{E}_{z} \bar{t}^{3}}{12\left(1-\bar{\nu}_{y z} \bar{\nu}_{z y}\right)}=E_{\mathrm{s}} I_{\mathrm{w}}=3.97 \times 10^{7} \mathrm{Nm}^{2} / \mathrm{m}
$$

Solving equations (2) and (10) and using Poisson's ratios of 0.3 , yields $\bar{t}=0.396 \mathrm{~m}$ and $\bar{E}_{y}=\bar{E}_{z}=6.99 \mathrm{GPa}$ for the isotropic plate model. Table 4 gives an overview of the model parameters for the cases considered in this paper.

\begin{tabular}{lcccccccccc}
\hline Model & Soil & $\begin{array}{c}d \\
{[\mathrm{~m}]}\end{array}$ & $\begin{array}{c}h \\
{[\mathrm{~m}]}\end{array}$ & $\begin{array}{c}\bar{t} \\
{[\mathrm{~m}]}\end{array}$ & $\begin{array}{c}E_{y} \\
{\left[\mathrm{~N} / \mathrm{m}^{2}\right]}\end{array}$ & $\begin{array}{c}E_{z} \\
{\left[\mathrm{~N} / \mathrm{m}^{2}\right]}\end{array}$ & $\begin{array}{c}\bar{\mu}_{y z} \\
{\left[\mathrm{~N} / \mathrm{m}^{2}\right]}\end{array}$ & $\begin{array}{c}\bar{\nu}_{y z} \\
{[-]}\end{array}$ & $\begin{array}{c}\bar{\nu}_{z y} \\
{[-]}\end{array}$ & $\begin{array}{c}\bar{\rho} \\
{\left[\mathrm{kg} / \mathrm{m}^{3}\right]}\end{array}$ \\
\hline 1 & halfspace & 5.60 & 12 & 0.396 & $6990 \times 10^{6}$ & $6990 \times 10^{6}$ & $2690 \times 10^{6}$ & 0.3 & 0.3 & 286.6 \\
2 & halfspace & 5.60 & 12 & 0.396 & $2.47 \times 10^{6}$ & $7680 \times 10^{9}$ & $68.9 \times 10^{6}$ & 0.0 & 0.0 & 286.6 \\
3 & Furet & 5.60 & 12 & 0.396 & $2.47 \times 10^{6}$ & $7680 \times 10^{6}$ & $68.9 \times 10^{6}$ & 0.0 & 0.0 & 286.6 \\
4 & Furet & 5.60 & 18 & 0.396 & $2.47 \times 10^{6}$ & $7680 \times 10^{6}$ & $68.9 \times 10^{6}$ & 0.0 & 0.0 & 286.6 \\
\hline
\end{tabular}

Table 4: Geometric parameters and material properties of the sheet pile wall models used.

The walls are modeled by means of 2-node isotropic or orthotropic shell elements. These elements are coupled to a conforming BE mesh for the surrounding soil. Green's functions for a layered halfspace are used as fundamental solutions in the BE formulation [49,60]. The boundary element mesh can therefore be limited to the interface between the wall and the soil. The FE and BE discretizations are adjusted to ensure that at least eight elements per shear wavelength are provided at each frequency (figure 11). Due to computational constraints, the calculations are limited to $50 \mathrm{~Hz}$ and $30 \mathrm{~Hz}$ for the $12 \mathrm{~m}$ and $18 \mathrm{~m}$ deep sheet 
pile walls, respectively.

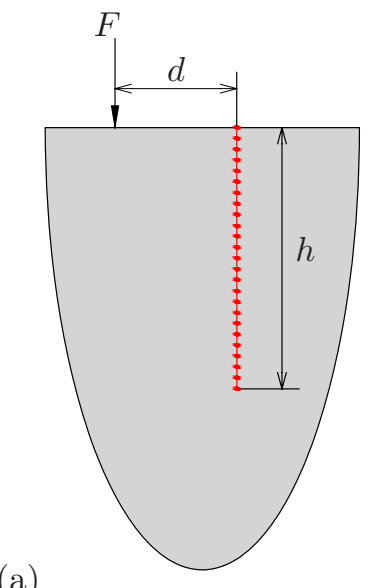

(a) (b)

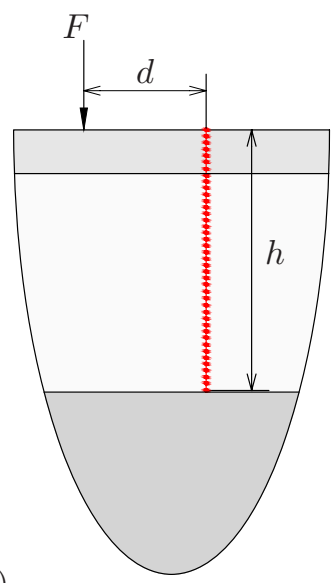

(c)

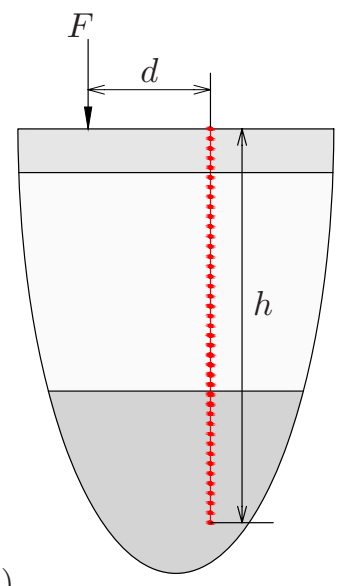

Figure 11: Mesh used for the wall in (a) model 1 and model 2, (b) model 3, and (c) model 4.

\subsection{Results for a homogeneous halfspace}

In this subsection, the vibration isolation efficiency of a sheet pile wall is investigated for the case of a homogeneous halfspace with dynamic soil characteristics corresponding to the underlying halfspace at the site of Furet (table 1). The results obtained with the isotropic and orthotropic wall model are compared to investigate the influence of the orthotropic behaviour of the sheet pile wall.

Figure 12 shows the vertical insertion loss for model 1 (isotropic plate) and model 2 (orthotropic plate) when a vertical harmonic point force with an excitation frequency of $25 \mathrm{~Hz}$ is applied at the soil's surface. For the isotropic model, a significant reduction of vibration levels is found in a delimited area behind the wall (figure 12a). The insertion loss reaches values of $10 \mathrm{~dB}$ and more in this region. Furthermore, a reduction of 3 to $5 \mathrm{~dB}$ can be noticed in the central zone, i.e. the zone around the line $y=0 \mathrm{~m}$, up to a depth of $5 \mathrm{~m}$. Lines of constructive and destructive interference between direct and reflected Rayleigh waves can be observed at the opposite side of the wall. At $25 \mathrm{~Hz}$, the insertion loss behind the wall is significantly lower for the orthotropic plate model (figure 12b). The orthotropic wall reduces the vibration levels at the surface around 3 to $5 \mathrm{~dB}$. The reduction in vibration levels behind the wall is relatively homogeneous at the soil's surface.

Two phenomena contribute independently to the wave impeding effect of stiff wave barriers [57]. First, the barrier behaves as a stiff beam embedded in a softer material and the transmission of surface waves is impeded when the trace wavelength of the incident waves is smaller than the bending wavelength in the beam [24]. The longitudinal bending stiffness thus hinders the transmission of Rayleigh waves impinging on the barrier at grazing incidence above a critical frequency. Rayleigh waves with a penetration depth much larger than the depth of the wall can be impeded. Secondly, when the depth of the wall is sufficiently large 


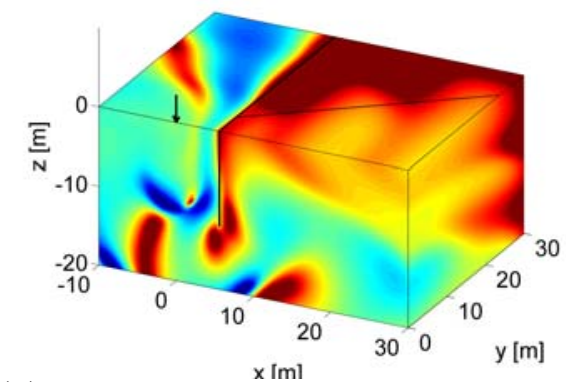

(a)

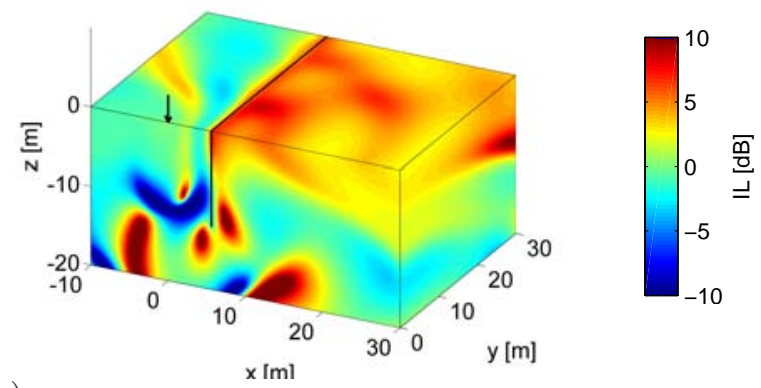

(b)

Figure 12: Vertical insertion loss of a $12 \mathrm{~m}$ deep sheet pile wall modelled as an (a) isotropic and (b) orthotropic plate for a point load applied at the soil's surface of a homogeneous halfspace at a frequency of $25 \mathrm{~Hz}$.

compared to the Rayleigh wavelength, waves impinging at normal incidence are also blocked. This reduction is also observed for open trenches $[6,17,33,35]$ and is almost independent of the angle of incidence.

For the isotropic wall, the first wave impeding effect is most important. The wall will mitigate vibrations above the critical frequency $f_{\mathrm{c}}$ at which the Rayleigh wavelength in the soil is equal to the free bending wavelength in the wall [24],

$$
f_{\mathrm{c}}=\frac{C_{\mathrm{R}}^{2}}{2 \pi} \sqrt{\frac{\rho_{\mathrm{w}} A_{\mathrm{w}}}{E_{\mathrm{w}} I_{\mathrm{w}}}}
$$

where $C_{\mathrm{R}}$ is the Rayleigh wave velocity of the soil, $\rho_{\mathrm{w}}$ the density of the wall, $A_{\mathrm{w}}$ the cross sectional area, $E_{\mathrm{w}}$ the Young's modulus and $I_{\mathrm{w}}$ the moment of inertia for bending around the horizontal $x-x$ or vertical $z-z$ axis:

$$
\begin{gathered}
I_{\mathrm{w}, x x}=\frac{t h^{3}}{12}, \\
I_{\mathrm{w}, z z}=\frac{h t^{3}}{12} .
\end{gathered}
$$

Using this rule of thumb, the isotropic wall is expected to mitigate vibrations above $9.6 \mathrm{~Hz}$, at which the Rayleigh wavelength in the soil is equal to the free bending wavelength in the wall for bending around the $z-z$ axis. Because the width of the wall is very small compared to the Rayleigh wavelength, bending waves for bending around the $x-x$ axis do not play a role [57]. The area for which a significant reduction of vibration levels is obtained above the critical frequency, is determined by a critical angle $\theta_{\mathrm{c}}[24]$ :

$$
\theta_{\mathrm{c}}=\sin ^{-1}\left(\frac{\lambda_{\mathrm{R}}}{\lambda_{\mathrm{b}}}\right)=\sin ^{-1}\left(C_{\mathrm{R}} \sqrt[4]{\frac{\rho_{\mathrm{w}} A_{\mathrm{w}}}{E_{\mathrm{w}} I_{\mathrm{w}, y} \omega^{2}}}\right)
$$

For the isotropic wall, the critical angle is equal to $38^{\circ}$ at $25 \mathrm{~Hz}$. This angle is also indicated on figure 12a.

Contrary to the results for the isotropic plate model, the reduction of vibration for the orthotropic wall is entirely due to the relatively high axial stiffness and bending stiffness around the $y-y$ axis [45]. The 
longitudinal bending stiffness of the orthotropic wall around the $z-z$ axis is far too low to affect the transmission of vibration in the frequency range of interest. As for the isotropic wall, the bending stiffness around the $x-x$ axis does not play a role due to the limited width of the wall. Only Rayleigh waves with a penetration depth smaller than the depth of the wall are efficiently reflected. It can be noted here that bending around the $z-z$ axis is incorporated in the models although the sheet piles are not rigidly connected over the entire length at the test site. Additional calculations [45] have shown that the influence of the bending stiffness $\bar{B}_{\mathrm{p} z}$ and, therefore, of the connection between the sheet piles on the insertion loss is negligible.

Figure 13 shows the vertical insertion loss for several receiver points behind the wall for model 1 and model 2 when the train load is applied. The insertion loss values are significantly higher for the isotropic plate model. The difference is larger for higher frequencies and for smaller distances from the wall. The isotropic wall is already effective at very low frequencies, especially for small distances from the wall. The insertion loss for a train load generally increases with frequency and decreases with increasing distance behind the wall, which can be understood by looking at the results in figure 12a. The central zone where a lower reduction of vibration levels is obtained increases with the distance from the track. This implies that at larger distances from the track, the contribution of a smaller number of axle loads will be mitigated. For the orthotropic plate model, very little vibration reduction is seen below $10 \mathrm{~Hz}$, especially at larger distances behind the

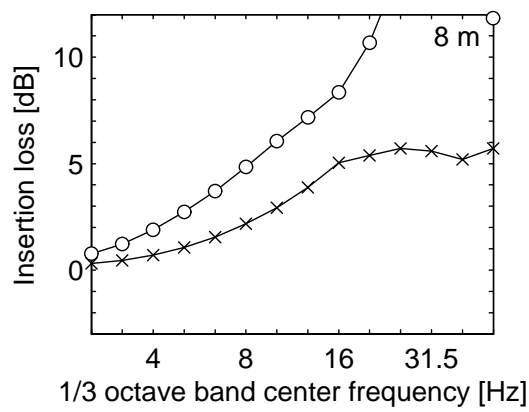

(a)
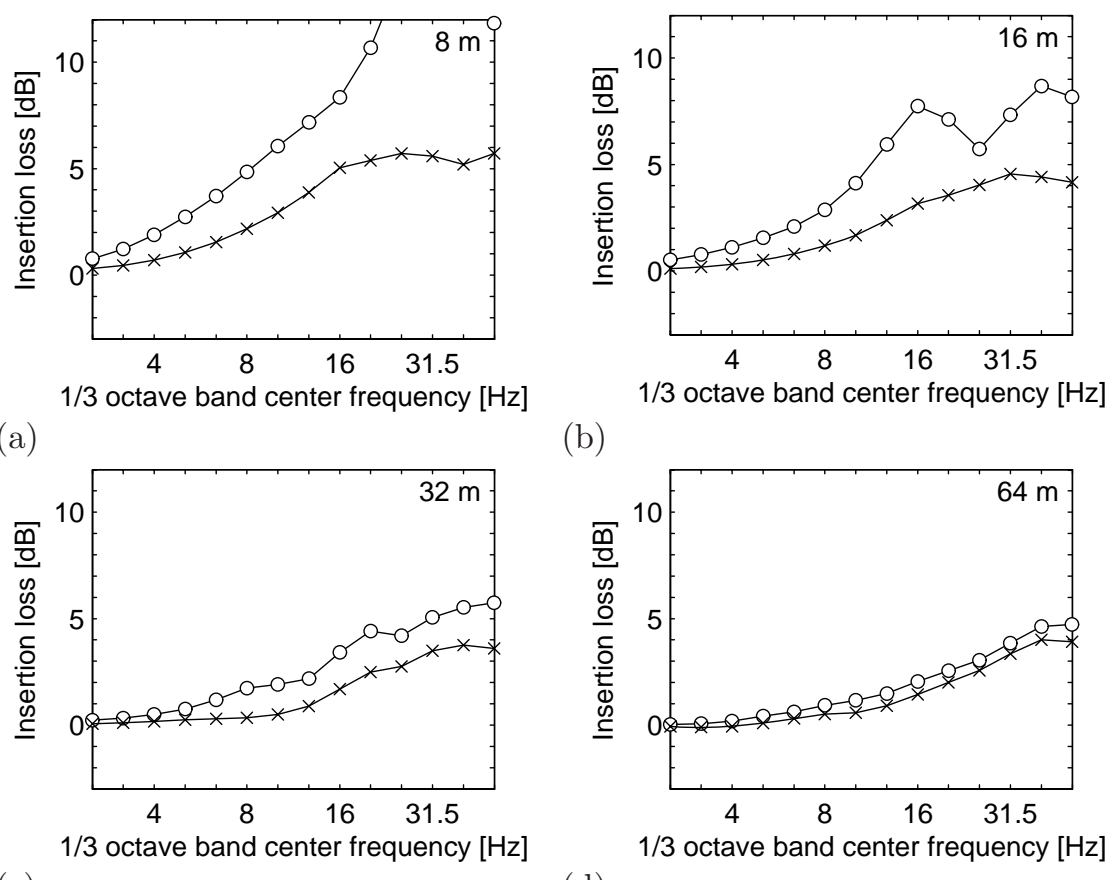

(b)

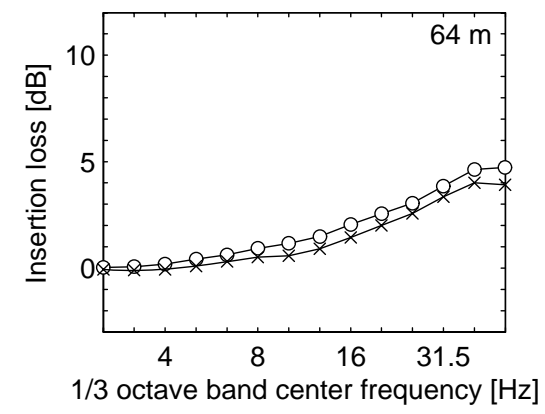

Figure 13: One-third octave band vertical insertion loss of a $12 \mathrm{~m}$ deep sheet pile wall modelled as an isotropic (o) and orthotropic plate $(\times)$ for a train load applied at the soil's surface of a homogeneous halfspace. Results at the soil's surface at $y=0 \mathrm{~m}$ and (a) $x=8 \mathrm{~m}$, (b) $x=16 \mathrm{~m}$, (c) $x=32 \mathrm{~m}$, and (d) $x=64 \mathrm{~m}$. 
wall. The reduction depends on the depth of the sheet pile wall relative to the Rayleigh wavelength. At $8 \mathrm{~m}$, insertion loss values of $3 \mathrm{~dB}$ and more are obtained above $10 \mathrm{~Hz}$. At this frequency, the ratio of the depth of the wall to the Rayleigh wavelength equals 0.65 for the homogeneous halfspace with a Rayleigh wave velocity of $187 \mathrm{~m} / \mathrm{s}$. At larger distances behind the wall, a reduction is only observed at higher frequencies due to possible diffraction around the bottom of the barrier. The insertion loss of the orthotropic wall increases slowly to an upper limit which is reached around $30 \mathrm{~Hz}$. This upper limit depends on the distance from the point load. At $8 \mathrm{~m}$, which is located $2.4 \mathrm{~m}$ behind the wall, a value of $6 \mathrm{~dB}$ is reached. At 32 and $64 \mathrm{~m}$, the insertion loss at high frequencies is limited to $4 \mathrm{~dB}$.

These results indicate that it is important to take into account the orthotropic behaviour of the sheet pile

wall when predicting its vibration reduction performance. The plate bending stiffness $\bar{B}_{\mathrm{p} y}$ in the longitudinal direction is strongly overestimated by the isotropic model for the sheet pile wall. As a result, the insertion loss for a train passage will also be strongly overestimated. The efficacy of the sheet pile wall is mainly determined by the depth of the wall relative to the Rayleigh wavelength in the soil.

\subsection{Results for the Furet test site}

In this subsection, the vibration isolation efficiency of the sheet pile wall installed at the test site in Furet is analyzed. A 3D analysis of the actual sheet pile wall with alternating depth of 12 and $18 \mathrm{~m}$ has not been performed in view of computation time and memory. Separate calculations have been made for uniform depths of $12 \mathrm{~m}$ (model 3 ) and $18 \mathrm{~m}$ (model 4 ) with the computationally more efficient 2.5D method. In both models, the sheet pile wall is modeled as an equivalent orthotropic plate (table 4).

Figure 14 shows the insertion loss for a $12 \mathrm{~m}$ deep sheet pile wall when a vertical harmonic point force is applied at the soil's surface with an excitation frequency of 5 and $25 \mathrm{~Hz}$. Figure 15 shows similar results for an $18 \mathrm{~m}$ deep wall. At $5 \mathrm{~Hz}$, the $12 \mathrm{~m}$ deep sheet pile wall only provides significant vibration reduction immediately behind the wall (figure 14a). At larger distances, the insertion loss is very limited. At $25 \mathrm{~Hz}$, the $12 \mathrm{~m}$ deep sheet pile wall reduces the vibration levels at the surface by more than $6 \mathrm{~dB}$ (figure 14b). This reduction is reasonably uniform along the soil's surface behind the sheet pile wall. It can be noticed, however, that the reduction in vibration levels is restricted to the top five meters of soil. For the $18 \mathrm{~m}$ deep sheet pile wall, a significant reduction is obtained at $5 \mathrm{~Hz}$ in the entire region behind the wall, although the insertion loss decreases with increasing distance (figure 15a). The higher efficacy compared to the $12 \mathrm{~m}$ deep sheet pile wall indicates that a significant amount of the vibrational energy passes underneath the $12 \mathrm{~m}$ deep wall at $5 \mathrm{~Hz}$. At $25 \mathrm{~Hz}$, the increased depth of the sheet pile wall does not significantly change the insertion loss (figure 15b). This may be explained by the fact that the motion of the Rayleigh waves is mainly limited to the top two layers at this frequency (figure 2). Therefore, the insertion loss is largely determined by the transmission of vibrations through the sheet pile wall.

Figure 16 shows the one-third octave band insertion loss of the $12 \mathrm{~m}$ and $18 \mathrm{~m}$ deep sheet pile wall for the 


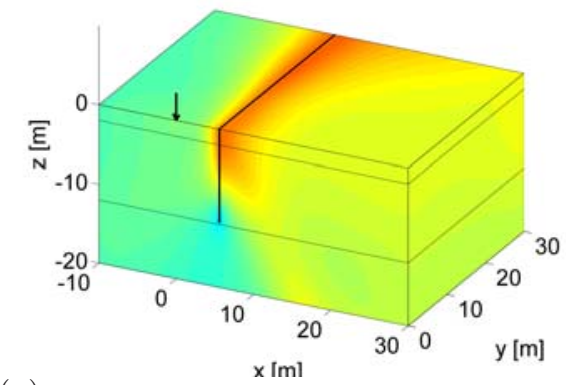

(a)

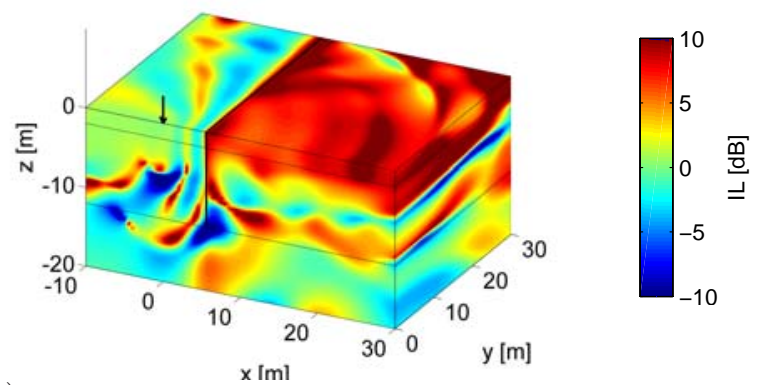

(b)

Figure 14: Vertical insertion loss of a $12 \mathrm{~m}$ deep sheet pile wall at the Furet site for a point load applied to the soil's surface at a frequency of (a) $5 \mathrm{~Hz}$ and (b) $25 \mathrm{~Hz}$.

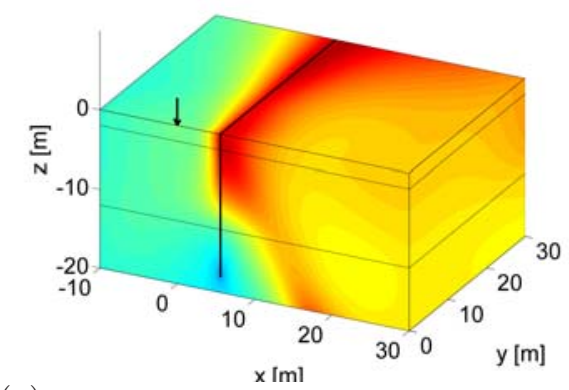

(a)

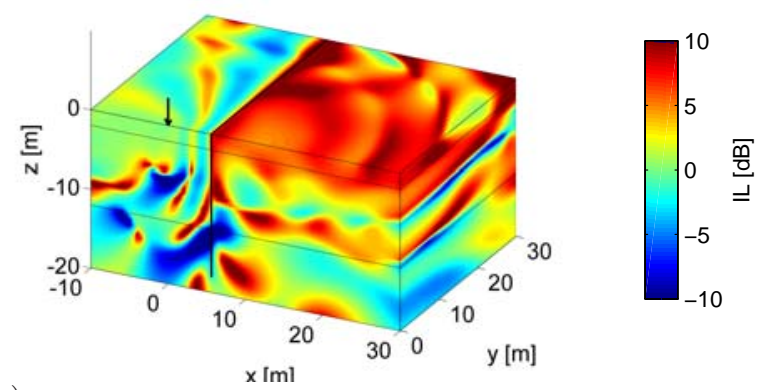

(b)

Figure 15: Vertical insertion loss of an $18 \mathrm{~m}$ deep sheet pile wall at the Furet site for a point load applied to the soil's surface at a frequency of (a) $5 \mathrm{~Hz}$ and (b) $25 \mathrm{~Hz}$.

train load at the Furet site. For positions at the same side of the sheet pile wall as the train load $(x=-16$ and $-8 \mathrm{~m}$ ), the vibration level is either increased or reduced due to constructive or destructive interference of the direct and reflected waves. The maximum increase in one-third octave band vibration levels remains relatively small however (figures 16a and 16b). Figures $16 \mathrm{c}$ to $16 \mathrm{f}$ show the predicted insertion loss for receivers at the other side of the sheet pile wall $(x=8,16,32$, and $64 \mathrm{~m})$. At very low frequencies, the wall has little effect on vibration transmission. At these frequencies, the wavelength and penetration depth of the Rayleigh waves are much larger than the depth of the walls (figure 2). Therefore, no or little effect of the wall on vibration transmission is expected. The sheet pile wall can effectively reduce the vibration levels at higher frequencies. Insertion loss values of $5 \mathrm{~dB}$ and more are predicted above $16 \mathrm{~Hz}$ for the $12 \mathrm{~m}$ deep sheet pile wall. It must be reminded, however, that the frequency range $4-5 \mathrm{~Hz}$ is targeted. Below $16 \mathrm{~Hz}$, the insertion loss is limited to $2 \mathrm{~dB}$ for the $12 \mathrm{~m}$ deep wall. Only for small distances behind the wall $(8 \mathrm{~m})$, the insertion loss can reach up to $4 \mathrm{~dB}$ below $10 \mathrm{~Hz}$. The results indicate that the increase in depth to $18 \mathrm{~m}$ has a favorable effect at low frequencies. The insertion loss is increased by $2 \mathrm{~dB}$ in the one-third octave bands between $4 \mathrm{~Hz}$ and $16 \mathrm{~Hz}$. Above $20 \mathrm{~Hz}$, the insertion loss is not improved. 


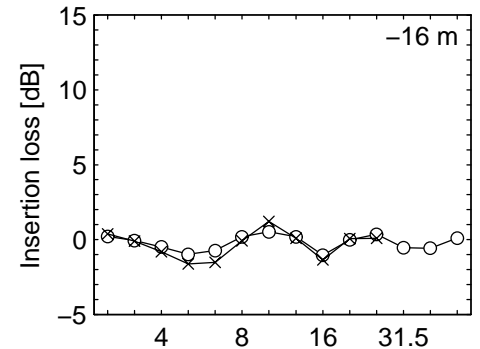

$1 / 3$ octave band center frequency $[\mathrm{Hz}]$

(a)

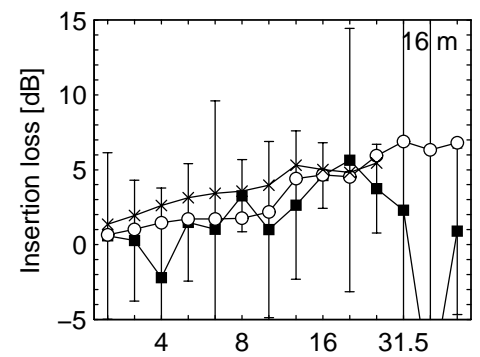

(d)

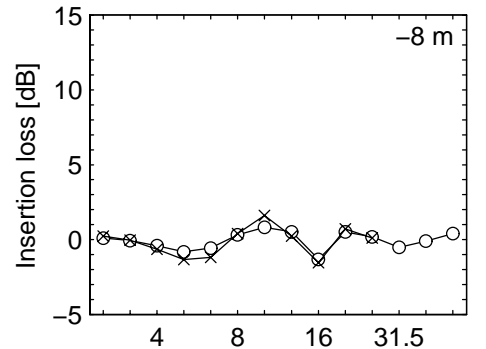

$1 / 3$ octave band center frequency [Hz]

(b)

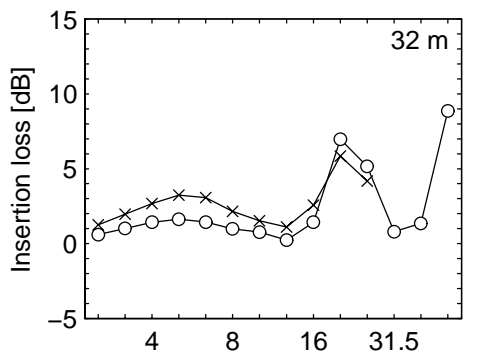

$1 / 3$ octave band center frequency [Hz]

(e)

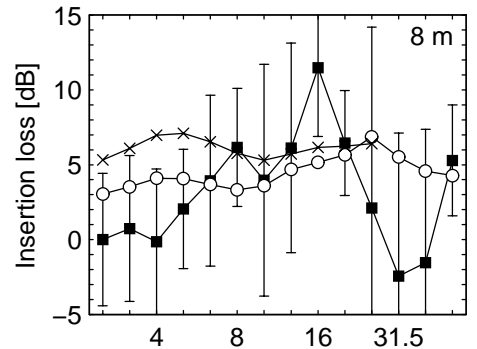

$1 / 3$ octave band center frequency $[\mathrm{Hz}]$

(c)

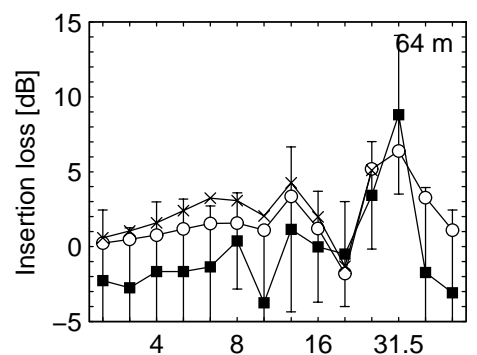

$1 / 3$ octave band center frequency $[\mathrm{Hz}]$

(f)

Figure 16: Simulated one-third octave band vertical insertion loss of a $12 \mathrm{~m}$ deep sheet pile wall (o) and an $18 \mathrm{~m}$ deep sheet pile wall $(\times)$ for a train load at the Furet site. Results at the soil's surface at $y=0 \mathrm{~m}$ and (a) $x=-16 \mathrm{~m}$, (b) $x=-8 \mathrm{~m}$, (c) $x=8 \mathrm{~m}$, (d) $x=16 \mathrm{~m}$, (e) $x=32 \mathrm{~m}$, and (f) $x=64 \mathrm{~m}$. The averaged measured vertical insertion loss for the X31 passenger trains $\overline{\mathrm{IL}}_{z}(f)(\boldsymbol{\square})$ and the $95 \%$ confidence interval estimates $\overline{\mathrm{IL}}_{z}(f) \pm \alpha \overline{\mathrm{IL}}_{z}$, tot $(f)$ of the measurements are superimposed.

The averaged measured insertion loss values for the X31 passenger trains $\overline{\mathrm{IL}}_{z}(f)$ and $95 \%$ confidence intervals $\overline{\mathrm{IL}}_{z}(f) \pm \alpha \sigma_{\overline{\mathrm{IL}}_{z} \text {,tot }}(f)$ are superimposed on figure 16. The measurement results for the freight trains have been discarded because of the very large uncertainty. The total uncertainty of the mean value $\sigma_{\overline{\mathrm{IL}}_{z}}$, tot is estimated as:

$$
\sigma_{\overline{\mathrm{IL}}_{z}, \text { tot }}(f)=\sqrt{\frac{1}{N_{\text {cat }}} \sum_{i=1}^{N_{\text {cat }}}\left(\frac{\sigma_{\mathrm{IL}_{z}, i}^{2}(f)}{n_{i}}\right)+\frac{\sigma_{\overline{\mathrm{IL}}_{z}}^{2}(f)}{N_{\text {cat }}}},
$$

with $N_{\text {cat }}$ the number of train categories, $n_{i}$ the number of train passages for train category $i, \sigma_{\mathrm{IL}_{z}, i}(f)$ the standard deviation of the insertion loss for train category $i$, and $\sigma_{\overline{\mathrm{IL}}_{z}}^{2}(f)$ the sample variance of the insertion loss for the different train catogeries. The first term under the square root in the right hand side of equation (15) represents the average uncertainty in the measured insertion loss for each train category, whereas the second term incorporates differences in insertion loss for the different train categories. Although the predicted insertion loss values show clear differences compared to the measured values, the agreement is generally good. Both measurements and simulations indicate that the sheet pile wall results in vibration reduction from $4 \mathrm{~Hz}$ upwards. Up to a frequency of $16-20 \mathrm{~Hz}$, the insertion loss values generally increase with frequency and decrease with distance from the sheet pile wall. The discrepancies between measured and predicted insertion loss are of the same order of magnitude as differences commonly found between 
measured and predicted railway induced vibration levels $[61,62]$. The predicted values are mostly within the confidence bounds of the measurement results, except around $31.5-40 \mathrm{~Hz}$. The measured negative insertion loss values in this frequency range are not observed in any predictions and are therefore believed to have other causes. Apart from measurement uncertainty, the discrepancies between the measurements and predictions could be due to simplifications introduced in the numerical model, such as the assumed uniform depth and infinite length of the wall. Furthermore, the track, which may influence the insertion loss at close distances behind the barrier [57] has been disregarded in the model. The reasonable agreement between measurements and simulations demonstrates that state-of-the-art numerical prediction models can be used for the reliable design of wave barriers like sheet pile walls.

\section{Conclusions}

At the site of Furet, a sheet pile wall was installed next to the track to reduce vibrations in buildings induced by passing trains. The depth of the sheet piles is $12 \mathrm{~m}$ with every fourth pile extended to $18 \mathrm{~m}$. The efficacy of the sheet pile wall is analyzed extensively by means of measurements and numerical simulations. The insertion loss has been measured by comparing the average vibration levels obtained before and after installation of the sheet pile wall according to the RIVAS measurement protocol.

The simulations show that the sheet pile wall acts as a stiff wave barrier and the efficacy is determined by the depth and the stiffness contrast between the barrier and the soil. The sheet pile wall is only effective when the depth of the sheet piles is sufficiently large compared to the Rayleigh wavelength in the soil. It is important to take into account the orthotropic behaviour of the sheet pile wall, as the plate bending stiffness with respect to the horizontal axis perpendicular to the profiles is much larger than the plate bending stiffness with respect to the vertical axis along the profiles. A simplified isotropic model does not allow accounting accurately for the transmission of waves at grazing incidence.

Although the measured and predicted insertion loss values show some clear differences, the general trends are similar. The sheet pile wall results in vibration reduction from $4 \mathrm{~Hz}$ upwards. Comparing the predicted insertion loss values for the two depths of the wall indicates this is largely thanks to the sheet piles reaching down to $18 \mathrm{~m}$ below the ground level. Up to a frequency of $16-20 \mathrm{~Hz}$, the predicted and measured insertion loss values generally increase with frequency and decrease with distance from the sheet pile wall.

It is concluded from the field test in Sweden that a sheet pile wall offers potential for vibration reduction in soft soil conditions, provided it is built sufficiently deep.

\section{Acknowledgements}

The first author is a postdoctoral fellow of the Research Foundation Flanders (FWO). The results have been obtained within the frame of the EU FP7 project RIVAS (Railway Induced Vibration Abatement 
Solutions) [44] under grant agreement No. 265754. The financial support is gratefully acknowledged.

\section{References}

[1] C. Jones, Use of numerical models to determine the effectiveness of anti-vibration systems for railways, Proceedings of the Institution of Civil Engineers-Transport 105 (1) (1994) 43-51.

[2] A. Kaynia, C. Madshus, P. Zackrisson, Ground vibration from high speed trains: prediction and countermeasure, Journal of Geotechnical and Geoenvironmental Engineering, Proceedings of the ASCE 126 (6) (2000) 531-537.

[3] D. Thompson, Railway noise and vibration: mechanisms, modelling, and means of control, Elsevier, Oxford, 2009.

[4] R. Hildebrand, Effect of soil stabilization on audible band railway ground vibration, Soil Dynamics and Earthquake Engineering 24 (2004) 411-424.

[5] H. Loy, Mitigating vibration using under-sleeper pads, Railway Gazette International 168 (4) (2012) 40-43.

[6] D. Beskos, B. Dasgupta, I. Vardoulakis, Vibration isolation using open or filled trenches. Part I: 2-D homogeneous soil, Computational Mechanics 1 (1986) 43-63.

[7] S. Ahmad, T. Al-Hussaini, Simplified design for vibration screening by open and in-filled trenches, Journal of Geotechnical Engineering, Proceedings of the ASCE 117 (1) (1991) 67-88.

[8] H. Hung, Y. Yang, D. Chang, Wave barriers for reduction of train-induced vibrations in soils, Journal of Geotechnical Engineering, Proceedings of the ASCE 130 (12) (2004) 1283-1291.

[9] X. Sheng, C. Jones, D. Thompson, Prediction of ground vibration from trains using the wavenumber finite and boundary element methods, Journal of Sound and Vibration 293 (2006) 575-586.

[10] V.V. Krylov, Control of traffic-induced ground vibrations by placing heavy masses on the ground surface, Journal of Low Frequency Noise, Vibration and Active Control 26 (4) (2007) 311-320.

[11] A. Dijckmans, P. Coulier, J. Jiang, M. Toward, D. Thompson, G. Degrande, G. Lombaert, Mitigation of railway induced ground vibration by heavy masses next to the track, Soil Dynamics and Earthquake Engineering 75 (2015) 158-170.

[12] A. Karlström, A. Boström, Efficiency of trenches along railways for trains moving at sub- or supersonic speeds, Soil Dynamics and Earthquake Engineering 27 (2007) 625-641.

[13] R. Shrivastava, N. Kameswara Rao, Response of soil media due to impulse loads and isolation using trenches, Soil Dynamics and Earthquake Engineering 22 (6) (2002) 695-702.

[14] P. Banerjee, S. Ahmad, K. Chen, Advanced application of BEM to wave barriers in multi-layered three-dimensional soil media, Earthquake Engineering and Structural Dynamics 16 (1988) 1041-1060.

[15] R. Klein, H. Antes, D. Le Houédec, Efficient 3D modelling of vibration isolation by open trenches, Computers and Structures 64 (1997) 809-817.

[16] L. Andersen, S. Nielsen, Reduction of ground vibration by means of barriers or soil improvement along a railway track, Soil Dynamics and Earthquake Engineering 25 (2005) 701-716.

[17] G. Segol, P. Lee, J. Abel, Amplitude reduction of surface waves by trenches, Journal of the Engineering Mechanics Division, Proceedings of the ASCE 104 (3) (1978) 621-641.

[18] C. Jones, D. Thompson, J. Andreu-Medina, Initial theoretical study of reducing surface-propagating vibration from trains using earthworks close to the track, in: Proceedings of the 8th International Conference on Structural Dynamics, EURODYN 2011, Leuven, Belgium, 2011, pp. 684-691.

[19] K. Leung, I. Vardoulakis, D. Beskos, Vibration isolation using open or filled trenches. Part III: 2-D nonhomogeneous soil, Computational Mechanics 7 (1990) 137-148.

[20] J. Jiang, M. Toward, A. Dijckmans, D. Thompson, G. Degrande, G. Lombaert, J. Ryue, Reducing railway induced groundborne vibration by using trenches and buried soft barriers, in: J. Nielsen, D. Anderson, P. de Vos, P.-E. Gautier, M. Iida, 
J. Nelson, T. Tielkes, D. Thompson, D. Towers (Eds.), Proceedings of the 11th International Workshop on Railway Noise IWRN11, Uddevalla, Sweden, 2013, pp. 615-622.

[21] P. Tsai, T. Chang, Effects of open trench siding on vibration-screening effectiveness using the two-dimensional boundary element method, Soil Dynamics and Earthquake Engineering 29 (5) (2009) 865-873.

[22] R. Hildebrand, Asymptotic analysis of hard wave barriers in soil, Soil Dynamics and Earthquake Engineering 23 (7) (2003) $143-158$.

[23] W. Haupt, Verhalten von Oberflächenwellen im inhomogenen Halbraum mit besonderer Berücksichtigung der Wellenabschirmung, Ph.D. thesis, Fakultät für Bauingenieurwezen, Universität Karlsruhe (1978).

[24] P. Coulier, S. François, G. Degrande, G. Lombaert, Subgrade stiffening next to the track as a wave impeding barrier for railway induced vibrations, Soil Dynamics and Earthquake Engineering 48 (2013) 119-131.

[25] S. François, M. Schevenels, B. Thyssen, J. Borgions, G. Degrande, Design and efficiency of a vibration isolating screen in the soil, Soil Dynamics and Earthquake Engineering 39 (2012) 113-127.

[26] M. Adam, O. von Estorff, Reduction of train-induced vibrations by using open and filled trenches, Computers and Structures 83 (2005) 11-24.

[27] B. Dasgupta, D. Beskos, I. Vardoulakis, Vibration isolation using open or filled trenches. Part II: 3-D homogeneous soil, Computational Mechanics 6 (1990) 129-142.

[28] P. Coulier, A. Dijckmans, S. François, G. Degrande, G. Lombaert, A spatial windowing technique to account for finite dimensions in 2.5D dynamic soil-structure interaction problems, Soil Dynamics and Earthquake Engineering 59 (2014) $51-67$.

[29] J. Aviles, F. Sanchez-Sesma, Foundation isolation from vibrations using piles as barriers, Journal of the Engineering Mechanics Division, Proceedings of the ASCE 114 (11) (1988) 1854-1870.

[30] S. Kattis, D. Polyzos, D. Beskos, Vibration isolation by a row of piles using a 3-D frequency domain BEM, International Journal for Numerical Methods in Engineering 46 (1999) 713-728.

[31] G. Gao, Z. Li, C. Qiu, Z. Yue, Three-dimensional analysis of rows of piles as passive barriers for ground vibration isolation, Soil Dynamics and Earthquake Engineering 26 (11) (2006) 1015-1027.

[32] S. Kattis, D. Polyzos, D. Beskos, Modelling of pile wave barriers by effective trenches and their screening effectiveness, Soil Dynamics and Earthquake Engineering 18 (1) (1999) 1-10.

[33] R. Woods, Screening of surface waves in soils, Journal of the Soil Mechanics and Foundation Division, Proceedings of the ASCE 94 (SM4) (1968) 951-979.

[34] H. Dolling, Abschirmung von Erschütterungen durch Bodenschlitze, Bautechnik 5 (1970) 151-158.

[35] F. Richart, J. Hall, R. Woods, Vibrations of soils and foundations, Prentice-Hall, Englewood Cliffs, New Jersey, 1970.

[36] A. Alzawi, M. El Naggar, Full scale experimental study on vibration scattering using open and in-filled (geofoam) wave barriers, Soil Dynamics and Earthquake Engineering 31 (3) (2011) 306-317.

[37] F. De Cock, C. Legrand, Influence of underground gas cushions on the wave propagation of ground vibrations, in: Proceedings of the 4th International Conference on the Application of Stress Wave Theory to Piles, The Hague, The Netherlands, 1992.

[38] K. Massarsch, Vibration isolation using gas-filled cushions, in: Proceedings of the Geo-Frontiers 2005 Congress, American Society of Civil Engineers, Austin, Texas, 2005.

[39] M. Kim, P. Lee, D. Kim, H. Kwon, Vibration isolation using flexible rubber chip barriers, in: G. Schmid, N. Chouw (Eds.), Proceedings of the International Workshop Wave 2000, Wave propagation, Moving load, Vibration reduction, A.A Balkema, Amsterdam, 2000, pp. 289-298.

[40] R. Wettschureck, D. Doberauer, W. Daiminger, Verminderung des vom Schienenverkehr ausgehenden Körperschalles. Untersuchungen zur Wirksamkeit eines elastischen Erdschlitzes seitlich einer oberirdischen Eisenbahnstrecke., Kurzbericht 
10.749/2, Müller-BBM GMBH (1985).

[41] E. Çelebi, S. Firat, G. Beyhan, İ. Çankaya, İ. Vural, O. Kirtel, Field experiments on wave propagation and vibration isolation by using wave barriers, Soil Dynamics and Earthquake Engineering 29 (5) (2009) 824-833.

[42] C. With, M. Bahrekazemi, A. Bodare, Wave barrier of lime-cement columns against train-induced ground-borne vibrations, Soil Dynamics and Earthquake Engineering 29 (6) (2009) 1027-1033.

[43] P. Coulier, V. Cuéllar, G. Degrande, G. Lombaert, Experimental and numerical evaluation of the effectiveness of a stiff wave barrier in the soil, Soil Dynamics and Earthquake Engineering, Soil Dynamics and Earthquake Engineering 77 (2015) 238-253.

[44] http://www.rivas-project.eu (2011).

[45] A. Dijckmans, A. Ekblad, A. Smekal, G. Degrande, G. Lombaert, A sheet piling wall as a wave barrier for train induced vibrations, in: M. Papadrakakis, V. Papadopoulos, V. Plevris (Eds.), Proceedings of the 4th International Conference On Computational Methods in Structural Dynamics and Earthquake Engineering, COMPDYN 2013, Kos Island, Greece, 2013, CD-ROM.

[46] A. Dijckmans, A. Ekblad, A. Smekal, G. Degrande, G. Lombaert, Mitigation of railway induced vibrations by use of a sheet pile wall, in: GEORAIL 2014. 2nd International Symposium on Railway Geotechnical Engineering, Marne-la-Vallée, France, 2014, pp. 515-524.

[47] Swedish Standards Institute, SS 46048 61: Vibrationer och stöt - mätning och riktvärden för bedömning av komfort i byggnader. [Vibration and shock - measurement and guideline for the assessment of comfort in buildings] (1992).

[48] P. Coulier, G. Degrande, A. Dijckmans, J. Houbrechts, G. Lombaert, W. Rücker, L. Auersch, M. Plaza, V. Cuéllar, D. Thompson, A. Ekblad, A. Smekal, Scope of the parametric study on mitigation measures on the transmission path, RIVAS project SCP0-GA-2010-265754, Deliverable D4.1, Report to the EC (October 2011).

[49] M. Schevenels, S. François, G. Degrande, EDT: An ElastoDynamics Toolbox for MATLAB, Computers \& Geosciences 35 (8) (2009) 1752-1754.

[50] K. Tokimatsu, S. Tamura, H. Kosjima, Effects of multiple modes on Rayleigh wave dispersion characteristics, Journal of Geotechnical Engineering, Proceedings of the ASCE 118 (10) (1992) 1529-1543.

[51] E. Poikolainen, Railway vibration and sheet pile walls in Finland, workshop RIVAS WP4, Frankfurt (June 2011).

[52] Itasca Consulting Group, Minneapolis: Itasca, FLAC3D - Fast Lagrangian Analysis of Continua in 3 Dimensions.

[53] D. Stiebel, B. Nelain, N. Vincent, How to measure and transfer efficiencies of vibration-mitigation measures: results of the European project RIVAS, in: P. Sas, D. Moens, S. Jonckheere (Eds.), Proceedings of ISMA 2012 International Conference on Noise and Vibration Engineering, Leuven, Belgium, 2012.

[54] A. Dijckmans, P. Coulier, G. Degrande, G. Lombaert, A. Ekblad, A. Smekal, M. Rodríguez Plaza, A. Andrés-Alguacil, V. Cuéllar, J. Keil, G. Vukotic, Mitigation measures on the transmission path: results of field tests, RIVAS project SCP0-GA-2010-265754, Deliverable D4.5, Report to the EC (December 2013).

[55] H. Cramér, Mathematical methods of statistics, Princeton University Press, Princeton, NJ, 1946.

[56] S. François, M. Schevenels, G. Lombaert, P. Galvín, G. Degrande, A 2.5D coupled FE-BE methodology for the dynamic interaction between longitudinally invariant structures and a layered halfspace, Computer Methods in Applied Mechanics and Engineering 199 (23-24) (2010) 1536-1548.

[57] A. Dijckmans, J. Jiang, M. Toward, G. Lombaert, G. Degrande, D. Thompson, Numerical study of vibration mitigation measures in the transmission path, RIVAS project SCP0-GA-2010-265754, Deliverable D4.4, Report to the EC (December 2013).

[58] H. Verbraken, G. Lombaert, G. Degrande, Verification of an empirical prediction method for railway induced vibrations by means of numerical simulations, Journal of Sound and Vibration 330 (8) (2011) 1692-1703.

[59] C. Hopkins, Sound insulation, Elsevier Ltd., Oxford, 2007. 
[60] E. Kausel, J. Roësset, Stiffness matrices for layered soils, Bulletin of the Seismological Society of America 71 (6) (1981) $1743-1761$.

[61] G. Lombaert, G. Degrande, J. Kogut, S. François, The experimental validation of a numerical model for the prediction of railway induced vibrations, Journal of Sound and Vibration 297 (3-5) (2006) 512-535.

[62] H. Hunt, M. Hussein, Vibration from railways: can we achieve better than $+/-10$ dB prediction accuracy?, in: 14th International Congress on Sound and Vibration, Cairns, Australia, 2007. 